\title{
The role of permanent and transitory components in business cycle volatility moderation.
}

\author{
Oleg Korenok \\ Department of Economics \\ Rutgers University \\ New Brunswick, NJ \\ E-mail: korenok@rci.rutgers.edu \\ Stanislav Radchenko \\ Department of Economics \\ University of North Carolina at Charlotte \\ Charlotte, NC 28223. \\ E-mail: sradchen@email.uncc.edu.
}

This version: January, 2004 


\begin{abstract}
The paper examines the processes underlying economic fluctuations by investigating the volatility moderation of U.S. economy in the early 1980's. We decompose the volatility decline using a dynamic factor framework into a common stochastic trend, common transitory component and idiosyncratic components. We find that the moderation of business cycle was a result of the moderation in transitory and idiosyncratic components. Our results suggest that important part of stochastic process that drives economy is transitory. The paper investigates the role of oil prices, monetary and financial market factors. Proposed economic factors do not have a significant relationship to either transitory or permanent components. In addition, we find that transitory shocks are as common during the 80's and 90's as they were during the 60's and 70's.
\end{abstract}

Keywords: volatility decline, great moderation, transitory shocks, asymmetry, factor models JEL Classification Numbers: C5, E3 


\section{Introduction}

There is disagreement among macroeconomists about whether macroeconomic shocks are permanent or transitory. The real business cycle (RBC) school focuses on large, persistent and cyclically volatile driving process which may be thought of as technology. On the other hand, monetarist and neo-Keynesian theories claim that the central role in economic fluctuations is played by the driving processes that are temporary (transitory) and may be thought of as shocks to aggregate demand, such as monetary policy shocks or animal spirits. This disagreement leads to important differences in the welfare evaluation of recessions. In the case of persistent fluctuations the loss in output of the economy is permanent, while in a case of transitory fluctuations, the loss is recovered after a recession ${ }^{1}$. This difference has profound effects on evaluations of anti-recession monetary and fiscal policies.

There are several studies which concentrate on the stochastic properties of fluctuations ${ }^{2}$ of economic time series from empirical prospective. Hamilton (1989) and McConnel and Perez-Quiros (2000) model fluctuations as movements in permanent trend with possible asymmetry $^{3}$. Unlike Hamilton (1989), Friedman (1964) finds that economic fluctuations are a result of large, negative movements in transitory component, "plucks", that cause output to deviate from persistent and perhaps random walk trend. Kim and Nelson (1999a) developed a model of fluctuations of univariate macroeconomic time series which has both

\footnotetext{
${ }^{1}$ Lucas (1987) finds that the 'small' shocks to permanent component have "enormous" effect to the welfare compared to the shocks to transitory component.

${ }^{2}$ These studies do not use structural models so that they do not distinguish whether particular behavior originates from the driving process or from the structure of the model. However, it is common to structural models that the stochastic properties of driving process are similar to the properties of resulted fluctuations. For example, describing RBC model King and Rebello (2000) state that "technology shocks are a dominant source of fluctuations".

${ }^{3}$ Kim and Nelson (1999a) and Kim and Murray (2002) provide an extensive list of references on asymmetry in the business cycle literature.
} 
the permanent and transitory components. Kim and Murray (2002) develop a multivariate model of macroeconomic time series fluctuations to study comovement among the series due to fluctuations in common permanent and transitory factors. This model allows the authors to measure the importance of each factor in explaining business cycle fluctuations over the time period analyzed.

Our paper continues this line of research by focusing on the role played by permanent and transitory factors during the volatility decline of early eighties. Kim and Nelson (1999b), McConnel and Perez-Quiros (2000), Stock and Watson (2002b, 2003) among others provide extensive evidence of the decline in volatility ${ }^{4}$. We believe that analysis of this important empirical regularity helps us to improve our understanding of the stochastic properties of economic fluctuations.

To achieve this goal, we introduce a time break in the model developed by Kim and Murray (2002) and compute the volatility decline. Next, we decompose the decline in the volatility of economic time series into the decline attributed to permanent, transitory and idiosyncratic components ${ }^{5}$. Finally, we estimate the influence of the following factors on the volatility moderation and common components: changes in oil prices, monetary and financial sector factors.

The approach taken here is different in several respects from previous literature. First, the model differs from Kim and Nelson (1999a) and Kim and Murray (2002) by focusing on particular empirical regularity, the volatility decline in early 1980's. This allows us to solve the puzzle raised by previous two papers which found no evidence of transitory shocks after early 1980's. Second, compared to the vector autoregression approach to the volatility decline of Stock and Watson (2002b, 2003) and Ahmed et al (2003), the application of factor

\footnotetext{
${ }^{4}$ A reader may consult Stock and Watson (2002b) for an extensive overview of the literature.

${ }^{5}$ Idiosyncratic component is usually ignored in business cycle literature since the literature focuses on fluctuations common to aggregate time series.
} 
model allows us to measure the role of common component in reduction of volatility, thus to distinguish the effect of business cycle fluctuations from idiosyncratic fluctuations.

To summarize our results, we find that less than $2 \%$ of the moderation ${ }^{6}$ can be attributed to the permanent factor while the transitory factor accounts for up to $75 \%$ of moderation for some variables. This finding supports previous Kim and Murray(2002) finding that the transitory factor plays an important role in characterization of the common fluctuations of US economy ${ }^{7}$. Additionally, we find that idiosyncratic shocks play a significant role (up to $68 \%$ for some series) in the moderation of early 80 's. If one is to view the idiosyncratic shocks as good luck then our finding confirms the finding of Stock and Watson (2002b, 2003) that "good luck" played an important role in the moderation of the volatility. We also find that proposed economic factors have weak individual explanatory power for the volatility decline in presence of transitory, permanent and idiosyncratic factors.

The structure of the paper is as follows. The description of the empirical method is given in Section 2. The results are presented and discussed in Section 3. The concluding remarks are in Section 4.

\section{The Econometric Model}

Our empirical approach is a dynamic factor model. Despite the popularity of other methods, Diebold and Rudebush (1996) argue that dynamic comovements among the large sets of macroeconomic variables are often well described by factor models, a particular configuration

\footnotetext{
${ }^{6}$ Moderation is a sum of common and idiosyncratic moderation for us. We use "common moderation" to talk about moderation resulting from a process that is common to all series.

${ }^{7}$ This finding is in contrast with the RBC literature findings of Prescott(1986) and Plosser (1989) who use a different framework and find that the model of economy which is driven only by persistent productivity shocks (Solow residual) produces fluctuations which are very close to business cycle fluctuations of real economy.
} 
of the vector autoregression. Recently, Kose et al. (2003) employ a dynamic factor model to estimate common components in macroeconomic aggregates in 60-country sample in order to investigate dynamic properties of business cycle fluctuations across countries and regions. Chauvet and Potter (2001) use one factor model to investigate the possible link between the reduction in volatility of the economic time series and the dynamics of the business cycle. Kim and Nelson (1999a) develop two factor model to estimate Friedman's plucking model of business cycle fluctuations. Kim and Murray (2002) extend the approach of Kim and Nelson (1999a) and decompose recessions into permanent and transitory components ${ }^{8}$.

We extend the dynamic factor model developed by Kim and Murray (2002). Based on the recent literature, we introduce a break in the model to allow for a volatility decline in common and idiosyncratic factors. We assume that each individual time series $y_{i t}$, for $i=1, \ldots, N$ could be represented as:

$$
y_{i t}=\gamma_{i} c_{t}+\nu_{i t}+\lambda_{i} x_{t}+\omega_{i t}+\zeta_{i} z_{t}
$$

where $c_{t}$ and $x_{t}$ are common permanent and transitory components, $\nu_{i t}$ and $\omega_{i t}$ are idiosyncratic permanent and transitory components error terms, $z_{t}$ is a common economic factor (i.e. oil price index, proxy of monetary policy etc), $\gamma_{i}, \lambda_{i}$ and $\zeta_{i}$ are factor loadings of permanent, transitory and economic factors, respectively. The factor loadings show extent to which each observed series is affected by the specific factor.

\footnotetext{
${ }^{8}$ There are numerous applications of factor models in the empirical macro and finance literature. Forni, Hallin, Lippi and Reichlin (2000) point out that the factor model can be used to learn about macroeconomic behavior on the basis of disaggregated data like sectors or regions. Bernanke et al. (2003) use a factor augmented vector autoregressive approach (FAVAR) to measure the effects of monetary policy. Marcellino et al. (2003) and Stock and Watson (2002a) show how one can apply the dynamic factor models in the macroeconomic forecasting. Bollerslev and Zhang (2003), Fama and French (1993, 1996) are examples of application of factor models in finance.
} 
Following the literature, we difference ${ }^{9}$ the variables to handle the integration problem of the observed series and write the model in the following form:

$$
\begin{aligned}
\Delta y_{i t} & =\gamma_{i} \triangle c_{t}+\lambda_{i} \triangle x_{t}+\zeta_{i} \triangle z_{t}+\eta_{i t} \\
\triangle c_{t} & =\phi \triangle c_{t-1}+\mu_{S_{1 t}}+v_{t} \\
\mu_{S_{1 t}} & =\mu_{0 t}+\mu_{1 t} S_{1 t} \\
x_{t} & =\phi^{*} x_{t-1}+\tau_{S_{2 t}}+u_{t} \\
\tau_{S_{2 t}} & =\tau_{t} S_{2 t} \\
\eta_{i t} & =\psi_{i} \eta_{i t-1}+e_{i t}
\end{aligned}
$$

where $i=1, \ldots, 4, v_{t} \sim N\left(0, \sigma_{v t}^{2}\right), u_{t} \sim N\left(0, \sigma_{u t}^{2}\right)$ and $e_{i t} \sim N\left(0, \sigma_{i t}^{2}\right)$ and

$$
\begin{aligned}
& \mu_{0 t}=\left\{\begin{array}{l}
\mu_{01} \text { if } t \leq T_{\text {break }} \\
\mu_{02} \text { if } t>T_{\text {break }}
\end{array} \mu_{1 t}=\left\{\begin{array}{l}
\mu_{11} \text { if } t \leq T_{\text {break }} \\
\mu_{12} \text { if } t>T_{\text {break }}
\end{array} \tau_{t}=\left\{\begin{array}{l}
\tau_{1} \text { if } t \leq T_{\text {break }} \\
\tau_{2} \text { if } t>T_{\text {break }}
\end{array}\right.\right.\right. \\
& \sigma_{v t}^{2}=\left\{\begin{array}{l}
\sigma_{v 1}^{2} \text { if } t \leq T_{\text {break }} \\
\sigma_{v 2}^{2} \text { if } t>T_{\text {break }}
\end{array} \sigma_{\text {it }}^{2}=\left\{\begin{array}{l}
\sigma_{i 1}^{2} \text { if } t \leq T_{\text {break }} \\
\sigma_{i 2}^{2} \text { if } t>T_{\text {break }}
\end{array} \sigma_{u t}^{2}=\left\{\begin{array}{l}
\sigma_{u 1}^{2} \text { if } t \leq T_{b r e a k} \\
\sigma_{u 2}^{2} \text { if } t>T_{\text {break }}
\end{array}\right.\right.\right.
\end{aligned}
$$

where $T_{\text {break }}$ is a date of the break which is assumed to be common for all the analyzed series. Equations (3) and (4) reproduce Hamilton (1989) regime switching of the common permanent component in which $\mu_{0 i}$ determines the growth rate of the permanent component during expansion and $\mu_{0 i}+\mu_{1 i}$ determines the growth rate of the permanent component during contraction, $\phi$ is a autoregression coefficient. Equations (5) and (6) model the Friedman (1964) regime switching of the common transitory component, whose mean is zero during expansion and negative during contraction.

The processes $S_{1 t}$ and $S_{2 t}$ are two-state Markov processes. The process $S_{1 t}$ takes on value zero if $S_{1 t}$ is in state one, expansion, and takes on value one if $S_{1 t}$ is in state two, contraction.

\footnotetext{
${ }^{9} \mathrm{We}$ do not have to demean the data in the analysis.
} 
The same applies to the process $S_{2 t}$, the process $S_{2 t}=0$ if $S_{2 t}$ is in state one, expansion, and $S_{2 t}=1$ if $S_{2 t}$ is in state two, contraction. Transition probability matrices for states $S_{1 t}$ and $S_{2 t}$ are $P_{1}$ and $P_{2}$ respectively. They are defined as follows:

$$
P_{1}=\left[\begin{array}{cc}
p_{11} & 1-p_{22} \\
1-p_{11} & p_{22}
\end{array}\right], P_{2}=\left[\begin{array}{cc}
q_{11} & 1-q_{22} \\
1-q_{11} & q_{22}
\end{array}\right]
$$

The assumption that the idiosyncratic factor $\eta_{i t}$ follows an $A R(1)$ process (equation (7)) is the same as in Kim and Murray (2002) who point out that results are not sensitive to the choice of $A R$ lag length.

As is well known the model (2) - (8) is not identified. To address the problem the variances of the permanent and transitory components for the first period are set to $\sigma_{v 1}^{2}=1 / 2$ and $\sigma_{u 1}^{2}=1 / 2$ which implies that:

$$
\sigma_{v t}^{2}=\left\{\begin{array}{c}
\frac{1}{2} \text { if } t \leq T_{\text {break }} \\
\frac{\sigma_{v 2}^{2}}{2 \sigma_{v 1}^{2}} \text { if } t>T_{\text {break }}
\end{array} \sigma_{u t}^{2}=\left\{\begin{array}{c}
\frac{1}{2} \text { if } t \leq T_{\text {break }} \\
\frac{\sigma_{u 2}^{2}}{2 \sigma_{u 1}^{2}} \text { if } t>T_{\text {break }}
\end{array}\right.\right.
$$

The model (2) - (10) reduces to the model analyzed by Kim and Murray (2002) when we impose the restrictions that $\zeta_{i}=0, \tau_{1}=\tau_{2}, \sigma_{i 1}^{2}=\sigma_{i 2}^{2}, \sigma_{u 1}^{2}=\sigma_{u 2}^{2}=1 / 2$ and $\sigma_{v 1}^{2}=$ $\sigma_{v 2}^{2}=1 / 2$ which imply that there are only two factors, permanent and transitory, that affect macroeconomic variables $y_{i t}$ and there is no break in the dynamics of permanent and transitory components.

From an econometric point of view, the main difference of the factor model that we consider from the model analyzed in the literature is that we allow a break in the dynamics of the permanent and transitory components. The model allows two sources of break in the volatility of the permanent and transitory components. The first source is the change in the conditional variance of the components. The second source comes from the change in size of the transitory shocks and size of the permanent shocks which is modeled as the break in conditional mean of the processes. Note that the model allows us to estimate the ratios of 
the conditional variances between two periods for the permanent and transitory components and they can be used to make inferences about a break in the conditional volatility of the transitory and permanent components.

From a economic point of view, the model allows us to investigate the role of the permanent and transitory components and idiosyncratic shocks in moderation of the business cycle. We also introduce economic factor $z_{t}$ in the model to investigate possible relation between $z_{t}$ and underlying common factors. Ideally, we would like to associate transitory or permanent components with fluctuations in observable economic variables like oil or stock prices. If they were highly correlated we may conclude that they were important factors in determining business cycle fluctuations.

We think that if the $z_{t}$ has a nontrivial effect on common fluctuations of US economy then either the permanent or the transitory component should capture it. If this is the case, then explicit introduction of $z_{t}$ as an additional factor in the model should affect the estimates of permanent, transitory or both components, their factor loadings and the variance decomposition which we describe bellow. If the estimates of three factor models are not significantly different from two factor model we may conclude that $z_{t}$ has not played an important role in business cycle dynamics and in the volatility decline. The same approach was applied by Kose et al. (2003), Liew and Vassalou (2000) and Raymond and Rich (1997). Kose et al. (2003) introduced German investment growth as a possible second world factor in the model and checked how this additional factor changed the original estimate of the world factor ${ }^{10}$.

\footnotetext{
${ }^{10}$ Liew and Vassalou (2000) analyze whether the returns on artificially constructed factors, returns on size and momentum portfolios, contain significant information about GDP growth in different countries when the business cycle variables are added into the model. Raymond and Rich (1997) extend the Markov switching model introduced by Hamilton (1989) to include changes in the oil prices. Authors argue that if oil prices were to effect the timing of recessions and expansions, then the Markov switching model with oil prices included should produce different estimates of the growth rates during expansion and recession than the
} 


\section{Specification of the Factor $z_{t}$}

We use several alternative specifications for the factor $z_{t}$. The first factor that we investigate is the changes in oil prices ${ }^{11}$. Since the paper by Hamilton (1983), which show that recessions in the US economy coincide with oil price increases, many papers have investigated the relationship between oil price changes and the fluctuations of US economy.

The most recent references are Hamilton (2003), Clements and Krolzig (2002), Hooker (1996), Hamilton (1996), Raymond and Rich (1997) among others. Hamilton (1996) argues that appropriately defined oil price increases, net oil price increases (NOPI), should be used in the analysis of the relation between oil prices and macroeconomic variables. The net oil price increase is equal to the value of the oil price increase if the current increase in the oil prices is greater than the maximum of the oil price increases over the last year. Otherwise, it is zero. We use NOPI series as a measure of changes in oil prices in our analysis ${ }^{12}$.

Most postwar US recessions have been preceded by rising interest rates which may induce one to conclude that most postwar recessions have been preceded by periods of monetary tightening. Therefore, another economic factor that we add to two factor model is the interest rate. The effect of monetary policy on the decreased volatility of the economic indicators using the VAR methodology was analyzed by Stock and Watson (2002b, 2003), Ahmed et al. (2002) and Cogley and Sargent (2001) among others. To analyze the effect of the fluctuations in interest rate, which include both fluctuations due to monetary policy and policy shocks, we introduce the lagged ${ }^{13}$ value of the Federal Funds rate in the model.

Another candidate for $z_{t}$ that we investigate is the returns on stock market. We are standard Hamilton Markov switching model.

${ }^{11}$ Stock and Watson (2002) investigate the effect of the commodity prices on the volatility decline of the macroeconomic variables.

${ }^{12}$ The results for a series of simple oil price changes are not substantially different.

${ }^{13}$ Leeper et al. (1996) argued that lagged value of the interest rate is an appropriate measure to use in the analysis and this identifying assumption is consistent with many recent VAR analysis. 
interested in the effect of stock returns on the business cycle because it is argued that some of the recessions were caused by the burst of the stock market bubbles ${ }^{14}$. It is also believed that the Asian crisis of 1998 had it origin in financial markets. As in the case with the interest rate, we include the lagged value of DJ index returns as an additional factor in the model. We think it is reasonable to assume that there is some lag in the effect of the stock market on macroeconomic variables.

\section{The Assumption about $T_{\text {break }}$}

To estimate the model, we assume that the break date, $T_{b r e a k}$, is known. It is possible to model the change in $\sigma_{i t}^{2}$ formally in spirit of McConnel and Perez-Quiros (2000) or Chauvet and Potter (2001) and estimate the model with the assumption that the break date is unknown. In our view, this would lead to unnecessary complication of the model. There seems to be consensus about the break date in the literature. McConnel and Perez-Quiros (2000) estimate the break date to be 1984:I, Stock and Watson (2002) estimate the break date at 1983:II with the $67 \%$ confidence interval 1982:IV - 1985:III. The estimates of the break date by Chauvet and Potter (2001) and Ahmed et al.(2002) are also within this confidence interval, 1983:IV and 1984:II respectively ${ }^{15}$. Therefore, we set $T_{\text {break }}=1984: 1$.

One more note is in order here. Stock and Watson (2002) present evidence that the break date for variance of the sales may be not early eighties but early nineties. We leave the possibility of the different break dates for different series for future research and assume that there is a single break date common to all the series considered.

\section{Variance decomposition}

\footnotetext{
${ }^{14}$ Mishkin and White (2002) have used historical approach to show that some of the stock market crashes lead to recessions.

${ }^{15}$ We must note that all the papers use the quarterly data to estimate the break date while we are using the monthly data in the estimation of the model.
} 
In order to evaluate the importance of the factors in explaining moderation of US economy in early 1980's we use the measure proposed by Kim and Murray (2002) and employed by Kose et al. (2003). The variance of the observable variables $y_{i t}$ can be written as:

$$
\begin{aligned}
\operatorname{var}\left(\triangle y_{i t}\right) & =\gamma_{i}^{2} \operatorname{var}\left(\triangle c_{t}\right)+\lambda_{i}^{2} \operatorname{var}\left(\triangle x_{t}\right)+\zeta_{i}^{2} \operatorname{var}\left(\triangle z_{t}\right) \\
& +2 \zeta_{i} \gamma_{i} \operatorname{cov}\left(\triangle c_{t}, \triangle z_{t}\right)+2 \zeta_{i} \lambda_{i} \operatorname{cov}\left(\triangle x_{t}, \triangle z_{t}\right)+\operatorname{var}\left(\eta_{i t}\right)
\end{aligned}
$$

Using (11) we decompose the variance of observed time series into the variance attributed to common permanent component, the variance attributed to common transitory component, the variance attributed to economic factor and the variance of idiosyncratic component.

Based on equation (11) we can evaluate the role that each component played in decline of the volatility of $y_{i t}$ for the period before the break date, $t<T_{b r e a k}$, and for the period after the break date $t>T_{\text {break }}$. Disregarding the effect of covariances ${ }^{16}$, the volatility decline can be written as:

$$
1 \approx \frac{\gamma_{i}^{2} \triangle \operatorname{var}\left(\triangle c_{t}\right)}{\triangle \operatorname{var}\left(\triangle y_{i t}\right)}+\frac{\lambda_{i}^{2} \triangle \operatorname{var}\left(\triangle x_{t}\right)}{\triangle \operatorname{var}\left(\triangle y_{i t}\right)}+\frac{\zeta_{i}^{2} \triangle \operatorname{var}\left(\triangle z_{t}\right)}{\triangle \operatorname{var}\left(\triangle y_{i t}\right)}+\frac{\triangle \operatorname{var}\left(\eta_{i t}\right)}{\triangle \operatorname{var}\left(\triangle y_{i t}\right)}
$$

where $\triangle \operatorname{var}\left(\triangle y_{i t}\right)=\operatorname{var}\left(\triangle y_{i t, I}\right)-\operatorname{var}\left(\triangle y_{i t, I I}\right), \operatorname{var}\left(\triangle y_{i t, I}\right)$ is the variance of $\triangle y_{i t}$ in the first period and $\operatorname{var}\left(\triangle y_{i t, I I}\right)$ is the variance of $\triangle y_{i t}$ in the second period and other variables are defined in the same manner. Note that it is possible that volatility of some factors may actually increase which means that the volatility decline of other factors may be higher than the volatility decline of $y_{i t}$.

Unlike the most of the literature, we estimate the importance of idiosyncratic components in economic fluctuations and the volatility decline. The earlier research did not consider idiosyncratic shocks because they are not common to all series and therefore are not part of

\footnotetext{
${ }^{16}$ We do not report the percentage of variation attributed to the covariance between the permanent and transitory factors and the economic factor since these covariances are small.
} 
business cycles ${ }^{17}$. However, we believe that the decline in the variance of the idiosyncratic shocks is a legitimate source of economic fluctuations and the volatility decline of the economic variables. Another reason for the inclusion of idiosyncratic shocks in the analysis is that it allows us to evaluate how much a researcher ignores if she concentrates only on the common fluctuations. The importance of idiosyncratic component was also analyzed in the variance decomposition by Kose et al. (2003).

Even though the role that idiosyncratic shocks may play in the economic fluctuations and volatility reduction has not been analyzed in the literature, we believe it is not a new idea. McConnel and Peres-Quiros (2000) proposed that new inventory management methods are the source of the reduction in volatility in GDP. One may view the new inventory methods as idiosyncratic shocks which may explain the decline in the volatility of GDP or other production series. Stock and Watson (2002b) argue that the reduction in volatility is widespread across sectors, across production and sales and the new inventory methods can not conceivably explain the volatility reduction in all series. As a result, the new inventory methods can be considered as shocks idiosyncratic to industrial production series.

\section{Model estimation and the prior specification}

Before we explain our choice of the prior distribution, let us introduce the following notation: $\gamma=\left[\gamma_{1}, \ldots \gamma_{n}\right]^{\prime}, \lambda=\left[\lambda_{1}, \ldots, \lambda_{n}\right]^{\prime}, \zeta=\left[\zeta_{1}, \ldots, \zeta_{n}\right]^{\prime}, \psi=\left[\psi_{1}, \ldots, \psi_{n}\right]^{\prime}, \Sigma=\left[\sigma_{i 1}^{2}, \ldots, \sigma_{n 1}^{2}, \sigma_{i 2}^{2}, \ldots, \sigma_{n 2}^{2}\right]^{\prime}$ and $\Upsilon=\left[\gamma, \lambda, \zeta, \psi, \mu_{01}, \mu_{02}, \mu_{11}, \mu_{12}, \tau_{1}, \tau_{2}, \Sigma, \phi, \phi^{*}, \frac{\sigma_{u 2}^{2}}{2 \sigma_{u 1}^{2}}, \frac{\sigma_{v 2}^{2}}{2 \sigma_{v 1}^{2}}, p_{11}, p_{22}, q_{11}, q_{22}\right]$, where $n=4$ in our model.

The prior distributions for the model parameters are presented in Table 1. To set hyperparameters in the prior distribution we use estimates reported in the literature. We impose prior restrictions $\mu_{0 I}<0, \mu_{1 I}<0, \mu_{0 I I}>0, \mu_{1 I I}>0, \tau_{1}<0, \tau_{2}<0$ which are necessary for the identification purposes. Note that prior distributions for the parameters $\mu_{0}, \mu_{1}$

\footnotetext{
${ }^{17}$ Burns and Mitchel (1946) define business cycle shocks as shocks common to all the series.
} 
and $\tau_{1}$ are the same before and after the break. We also impose a prior restriction that the first difference of the permanent component and the level of the transitory component are covariance-stationary processes, $|\phi|<1$ and $\left|\phi^{*}\right|<1$ respectively. The parameters $\sigma_{i j}^{2}$, $i=1, \ldots, n$ and $j=1,2$ have Jeffreys prior distributions. Parameters $p_{i i}, q_{i i}$ follow Beta distribution with mean $E\left(p_{11}\right)=E\left(q_{11}\right)=0.9$ and $E\left(p_{22}\right)=E\left(q_{22}\right)=0.8$.

We estimate the state space model model (2) -(7) with Markov switching (9) using a modification of the Bayesian method presented in Kim and Nelson (1998). The detailed description of the state space representation and the Gibbs sampling algorithm are presented in the Appendix.

We construct a chain of 10,000 draws using Gibbs-sampling algorithm. The first 2,000 draws are discarded as a burn-in phase. We use the estimates of the parameters reported in the literature as a starting point for the chain. Standard techniques are used to test the convergence of Gibbs sampling chains to posterior distributions.

Several factor models are estimated. We use a two factor model with permanent and transitory factors and the break as the benchmark model (BM). We compare the results of our model with the results of model without the break as in Kim and Murray (2002) (KM). Next, we add economic variable $z_{t}$ as an additional factor in the model and estimate several three-factor models in order to investigate the possible relationship between the variable $z_{t}$ and common factors. We compare results from those models with BM results.

\section{Data and the Results}

We use monthly data on four series the index of industrial production, personal income less transfer payments, manufacturing and trade sales, and civilian labor force employed in nonagricultural industries for the period 1959:01-2002:12. For ease of presentation, we call the series on civilian labor force employed in nonagricultural industries as the employment 
series. The data on industrial production, personal income, manufacturing and trade sales and employment are obtained from the NBER website ${ }^{18}$. The data for the price of Domestic West Texas Intermediate was obtained from Federal Reserve Bank of St. Louis ${ }^{19}$. The data on the Dow Jones index was obtained from Yahoo financial service.

Our first finding is that the hypothesis of a break in the conditional mean of transitory component, or "pluck", is supported by the data. We find only a weak support, however, for the break in the conditional mean of permanent component. The size of the "pluck" of the transitory component during contractions and growth rates of the permanent component during expansions and contractions are reported in Table 3. The conditional mean of transitory component decreases from $\tau_{1}=-4.148$ during contractions in Period I to $\tau_{2}=-1.677$ during contractions in period II. Both estimates are statistically significant and one may reject the hypothesis that $\tau_{1}$ is equal to $\tau_{2}$. The size of the conditional mean of the permanent component during expansion decreases from $\mu_{0 I}=1.185$ in Period I to $\mu_{0 I I}=0.73$ in period II and it increases from $\mu_{1 I}=-2.226$ in Period I to $\mu_{1 I I}=-1.813$ in period II during contractions. These estimates are statistically significant but one can not reject the hypothesis of constancy of the conditional mean of the permanent component across two periods.

The evidence on the break in the conditional variance of the transitory component and the permanent component is reported in Table 3. The ratio of the conditional variance of the transitory component in the second period to the conditional variance of the transitory component in first period, $\frac{\sigma_{u, 2}^{2}}{\sigma_{u, 1}^{2}}$, is 0.184 , indicating a more than five time decrease in the variance of the error term. The same ratio for the permanent component, $\frac{\sigma_{v, 2}^{2}}{\sigma_{v, 1}^{2}}$, is 0.394 , indicating a more than two time decrease in the variance of the error term.

The decline in the conditional mean and the conditional variance across two periods

\footnotetext{
${ }^{18}$ The data may be found through the following link http://www.nber.org/cycles/hall.xlw.

${ }^{19}$ The data may be found through the FreeLunch web site http://www.economy.com/freelunch.
} 
leads to a decrease in the variance of transitory component from $\operatorname{var}\left(\triangle x_{t}\right)=1.77$ in period I to $\operatorname{var}\left(\triangle x_{t}\right)=0.20$ in period II. The relative decline in the variance of the permanent component is smaller. It decreases from $\operatorname{var}\left(\Delta c_{t}\right)=20.82$ in period I to $\operatorname{var}\left(\triangle c_{t}\right)=14.17$ in period II. These results are presented in Table 2 and one may observe the change in the dynamics of the transitory component after early 80's in Figure 1.

We find mixed evidence of the break in the variance of idiosyncratic component. The idiosyncratic variances decrease for the industrial production and employment series. However, there seems to be no decline in the idiosyncratic variances of the personal income and sales series.

Overall, we find a strong support for the break in the behavior of the transitory component while support for the break in the dynamics of the permanent component is weak. The change in the permanent component seems to come only from the change in the conditional variance. The change in the dynamics of the transitory component comes from the change in the conditional variance as well as the change in mean.

Based on the evidence of breaks in dynamics of the permanent and the transitory components, we estimate and compare the variance decomposition of the analyzed series across two time periods. This allows us to measure dynamics of the relative importance of common and idiosyncratic component. We present the relative contribution of the factors to variances of $y_{i t}$ in Table 5. One may notice considerable change in the role played by permanent and transitory components, idiosyncratic shocks across two periods. The transitory component explains from $27 \%$ of total variation for personal income to $69 \%^{20}$ of total variation for industrial production in period I. However, the significance of the transitory component declines in the second period because the share of the transitory component decreases in period II and it explains from $6 \%$ of variation for employment to $32 \%$ of variation for industrial pro-

\footnotetext{
${ }^{20}$ The range that we report is the lowest and the highest attribution across four series under investigation.
} 
duction. The share of the permanent component in total variation moves in the opposite direction to the transitory component, it increases from $4 \%-24 \%$ in period I to $24 \%-78 \%$ in period II. Idiosyncratic variances explain $26 \%$ - $65 \%$ of total variation during period I and $14 \%-52 \%$ during period II.

The variance decomposition results that we obtain in the first period are close to the results obtained by Kim and Murray (2002) ${ }^{21}$ and Cochrane (1994) who estimated that 70$80 \%$ of the variance of GNP growth may be attributed to the transitory shocks. On the other hand, the share explained by transitory factor in total variation during the second period is lower than in the first period. To explore this finding we now turn to discussion of the role played by permanent and transitory and idiosyncratic components in the volatility moderation.

Decomposition of variance moderation of individual time series into moderation due to permanent, transitory and idiosyncratic components is reported in Table 6. According to our estimates, the decline in the volatility of the transitory component explains $31 \%$ $75 \%$ of the decline in the volatility of economic variables. The decline in the variance of idiosyncratic shocks explains $24 \%-68 \%$ of the volatility decline. Moderation in volatility due to the permanent component is small $0.1 \%-1.44 \%$. We believe that large moderation of the transitory component and small moderation of the permanent component explain our previous findings that the permanent component becomes more important and the transitory component becomes less important in the second period.

From the decomposition of volatility moderation we conclude that the volatility decline was indeed the business cycle event with common components explaining 33\%-77\% of the volatility decline. We also conclude that the transitory component was the main factor in business cycle volatility decline while the influence of permanent component was weak. The

\footnotetext{
${ }^{21}$ Note that if we exclude idiosyncratic shocks from the variance decomposition, then the transitory component explains $60-90 \%$ of the variation which is in line with the results reported by Kim and Murray.
} 
above conclusion suggests that stochastic process that underlies economic fluctuations is mainly transitory.

Lucas (1987) with simple assumptions about utility function and representative agent showed that if recessions are $100 \%$ transitory they have very small welfare consequences for consumers. In a later survey Lucas (2003) points out that this conclusion holds for a wider class of utility functions and assumptions about agents heterogeneity. In our paper we find that the transitory component indeed plays an important role, but we find a significant permanent effect of recessions. Even though the effect of permanent component on volatility is small, further analysis is needed for the quantitative welfare evaluation of permanent component. However, we would like to point out that even small changes in permanent component can have substantial welfare consequences for consumers as it was pointed out in Lucas (1987).

We also would like to make several additional comments. First, we want to point out that the reduction in idiosyncratic variance plays a nontrivial role in volatility moderation. From this finding we conclude that theories which emphasize changes in idiosyncratic components in explaining volatility decline may be successful.

Second, looking at the estimates of the contraction in the transitory component, Figure 1 , one may notice that not all the transitory shocks lead to recessions ${ }^{22}$. We find many more transitory shocks then recessions, even though most of the recessions coincide with significant decline in the transitory component

Third, we find that formal incorporation of the break into our empirical model is essential in estimating transitory shocks after the 1980's. We present the estimates of the transitory and permanent component using BM without breaks in Figures 3 - 4. This model was estimated by Kim and Murray (2002) who do not find transitory shocks after 1980's.

\footnotetext{
${ }^{22}$ This can be more clearly seen by looking at the transitory component dynamics rather than at the smoothed probability of its contractions.
} 


\section{BM model with an additional factor}

The results of estimation of the BM models with additional economic factor ${ }^{23}$ are reported in Tables 2 - 12 and Figure 1.

The results from three factor models can be summarized as follows. First, the additional factor does not significantly change either the estimates of the permanent and transitory components or the estimates of the factor loadings. This can be seen from Figure 1 and Table 4. Second, none of the additional economic factors have significant factor loadings for all four series (Table 4). The factor loading for the oil prices has the expected signs for all the variables, however, only the factor loading on personal income series is statistically significant. The interest rate has a significant factor loading only for the employment series. Dow Jones index returns have significant factor loadings for industrial production, personal income and manufacturing and trade sales. Third, it can be seen from Tables 6-8 that economics factors do not play an important role in the variance decomposition. The percentage of total variance attributed to oil prices is $0.1-6 \%$, to interest rate $0-2.49 \%$ and to Dow Jones index returns is $0-0.84 \%$. Fourth, the additional factor does not seem to explain the volatility decline of the economic series in early 80's independently of transitory and permanent components. In nine cases out of twelve (Tables 2 - 12 ) the moderation of volatility explained by economic factor is close to zero with the only exception is the $9 \%$ decline in volatility of personal income attributed to the oil prices.

These results make us conclude that proposed economic factors do not have significant relationship to either transitory or permanent component. Our interpretation of this finding is that different transitory shocks have a different origin ${ }^{24}$ and it is not possible to explain

\footnotetext{
${ }^{23}$ We denote estimates of the model with changes in price of oil as Oil, estimates of the model with lagged FED interest rate as Interest Rate and estimates of the model with Dow Jones stock index as DJ.

${ }^{24}$ This interpretation is close to empirical findings of Cochrane (1994), see also Temin (1998), who does narrative investigation on the origin of different exogenous shocks in U.S. economy.
} 
the behavior of transitory factor by individual economic variable.

\section{Conclusions}

This section summarizes our findings and conclusions. First, our main conclusion is that important part of stochastic process that underlies economic fluctuations is transitory. It is based on our finding that transitory factor explains up to $75 \%$ of the decline in the total volatility of economic series in early 1980's. This conclusion corroborates the conclusions of Kim and Murray (2002) and Kim and Nelson (1999) that "during recessionary and highgrowth recovery periods, real GDP is driven mostly by transitory shocks".

Second, we find that a significant part of the total decline in the volatility is due to the idiosyncratic shocks. This result suggests that despite the fact that business cycle literature focuses on fluctuations common to all series, significant part of the moderation of early 80's had idiosyncratic origin. If one is to understand the reasons behind the moderation one needs to better understand idiosyncratic component fluctuations.

Third, we fail to attribute the moderation of business cycle to one of the observed eco-

nomic source of business cycle shocks. Proposed economic factors, oil prices, interest rate and stock market returns, do not have a significant relationship to either transitory or permanent component. We interpret this finding as the evidence that different transitory shocks may have different origin.

Additionally, we find that not all the transitory shocks necessarily lead or coincide with the NBER chronology of recessions. On the other hand, contractions of the permanent factor seem to coincide with the NBER reference business cycle well.

Finally, we show that the transitory shocks are as common during the 80's and 90's as they were during the 60's and 70's but the size of the transitory factor has declined considerably in the last two decades. 


\section{Appendix A: estimation of a multivariate Markov Switch- ing models}

We use a modified version of the Bayesian estimation procedure to estimate state-space models with Markov Switching proposed by Kim and Nelson (1998). We extend it to incorporate a known break date and additional economic variable.

The econometric model is:

$$
\begin{aligned}
\Delta y_{i t} & =\gamma_{i} \triangle c_{t}+\lambda_{i} \triangle x_{t}+\zeta_{i} z_{t}+\eta_{i t} \\
c_{t} & =\phi \triangle c_{t-1}+\mu_{S_{1 t}}+v_{t} \\
\mu_{S_{1 t}} & =\mu_{0}+\mu_{1} S_{1 t} \\
x_{t} & =\phi^{*} x_{t-1}+\tau_{S_{2 t}}+u_{t} \\
\tau_{S_{2 t}} & =\tau_{t} S_{2 t} \\
\eta_{i t} & =\psi_{i} \eta_{i t-1}+e_{i t}
\end{aligned}
$$

where $v_{t} \sim N(0,1), u_{t} \sim N\left(0, \sigma_{u t}^{2}\right), e_{i t} \sim N\left(0, \sigma_{i t}^{2}\right)$ and

$$
\sigma_{i t}^{2}=\left\{\begin{array}{l}
\sigma_{i 1}^{2} \text { if } t \leq T_{\text {break }} \\
\sigma_{i 2}^{2} \text { if } t>T_{\text {break }}
\end{array} \tau_{t}=\left\{\begin{array}{l}
\tau_{1} \text { if } t \leq T_{\text {break }} \\
\tau_{2} \text { if } t>T_{\text {break }}
\end{array} \quad \sigma_{u t}^{2}=\left\{\begin{array}{l}
1 / 2 \text { if } t \leq T_{\text {break }} \\
\frac{\sigma_{u 2}^{2}}{2 \sigma_{u 1}^{2}} \text { if } t>T_{\text {break }}
\end{array}\right.\right.\right.
$$

We estimate the model (A1) -(A6) to find posterior distributions of the parameters $\Upsilon=$

$\left[\gamma, \lambda, \zeta, \psi, \mu_{0}, \mu_{1}, \tau_{1}, \Sigma, \phi, \phi^{*}, \frac{\sigma_{u 2}^{2}}{2 \sigma_{u 1}^{2}}, p_{11}, p_{22}, q_{11}, q_{22}\right]$, and the unobserved state variables $c_{t}, x_{t}$ and $S_{1 t}$ and $S_{2 t}$.

We use the equivalent state space representation of the model to estimate the parameters $\Upsilon$ and the state variables $S_{1 t}, S_{2 t}$ : 


$$
\begin{aligned}
\triangle y_{t}^{*} & =H \xi_{t}+\zeta_{i} \triangle z_{t}^{*}+E_{t} \\
\xi_{t} & =\alpha_{S_{1 t}, S_{3 t}}+F \xi_{t-1}+V_{t} \\
E\left(V_{t} V_{t}^{\prime}\right) & =Q \\
E\left(E_{t} E_{t}^{\prime}\right) & =R
\end{aligned}
$$

where $\triangle y_{t}^{*}=\triangle y_{t}-\psi_{1} \triangle y_{t-1}$ is a $n \times 1$ observation vector, $\triangle z_{t}^{*}=\triangle z_{t}-\psi_{1} \triangle z_{t-1}$ is a $n \times 1$ observation vector, $E_{t}=\left[e_{1 t}, \ldots, e_{n t}\right]^{\prime}, \xi_{t}$ is a $k \times 1$ state vector, $V_{t}$ is a $k \times 1$ vector of disturbances, $H$ is a $n \times k$ matrix of the parameters and $R$ is an $n \times n$ diagonal variancecovariance matrix, $F$ and $Q$ are $k \times k$ matrices of the parameters. We used the following definitions in (A8) - (A11) :

$$
\begin{gathered}
\xi_{t}=\left[\begin{array}{c}
\Delta c_{t} \\
\triangle x_{t} \\
\Delta c_{t-1} \\
\Delta x_{t-1}
\end{array}\right], \quad \alpha_{S_{1 t}, S_{3 t}}=\left[\begin{array}{c}
\mu_{S_{1 t}} \\
\tau_{t, S_{3 t}} \\
0 \\
0
\end{array}\right], V_{t}=\left[\begin{array}{c}
v_{t} \\
\tilde{u}_{t} \\
0 \\
0
\end{array}\right] \\
H=\left[\begin{array}{cccc}
\gamma_{1} & \lambda_{1} & -\gamma_{1} \psi_{1} & -\lambda_{1} \psi_{1} \\
\gamma_{2} & \lambda_{2} & -\gamma_{2} \psi_{2} & -\lambda_{2} \psi_{2} \\
\gamma_{3} & \lambda_{3} & -\gamma_{3} \psi_{3} & -\lambda_{3} \psi_{3} \\
\gamma_{4} & \lambda_{4} & -\gamma_{1} \psi_{1} & -\lambda_{4} \psi_{4}
\end{array}\right], \text { zeta }=\left[\begin{array}{c}
\zeta_{1} \\
\zeta_{2} \\
\zeta_{3} \\
\zeta_{4}
\end{array}\right]
\end{gathered}
$$

and

$$
F=\left[\begin{array}{cccc}
\phi & 0 & 0 & 0 \\
0 & \phi^{*} & 0 & 0 \\
1 & 0 & 0 & 0 \\
0 & 1 & 0 & 0
\end{array}\right], Q=\left[\begin{array}{cccc}
1 & 0 & 0 & 0 \\
0 & 2 \sigma_{u t}^{2} & 0 & 0 \\
0 & 0 & 0 & 0 \\
0 & 0 & 0 & 0
\end{array}\right]
$$


where $S_{3 t}=S_{2 t}-S_{2 t-1}, \tilde{u}_{t}=u_{t}-u_{t-1}$. To derive this state space model one needs to note that:

$$
\begin{aligned}
\triangle x_{t} & =\phi^{*} \triangle x_{t-1}+\tau_{t}\left(S_{2 t}-S_{2 t-1}\right)+u_{t}-u_{t-1} \\
& =\phi^{*} \triangle x_{t-1}+\tau_{t} S_{3 t}+\tilde{u}_{t}
\end{aligned}
$$

The state variable $S_{3 t}$ is a four-state Markov process. The definition of states for the process $S_{3 t}$ is given in Table 13 and the transition probability for the process $S_{3 t}$ is given as follows:

$$
P_{3}=\left[\begin{array}{cccc}
0 & 0 & 1-q_{22} & 1-q_{22} \\
q_{11} & q_{11} & 0 & 0 \\
0 & 0 & q_{22} & q_{22} \\
1-q_{11} & 1-q_{11} & 0 & 0
\end{array}\right]
$$

The transition probability $P_{3}$ is easily derived if one notes that:

$$
\begin{aligned}
& \operatorname{Pr}\left(S_{3 t}=1 \mid S_{3 t-1}=1\right)=\operatorname{Pr}\left(S_{2 t}=1, S_{2 t-1}=2 \mid S_{2 t-1}=1, S_{2 t-2}=2\right)=0 \\
& \operatorname{Pr}\left(S_{3 t}=2 \mid S_{3 t-1}=1\right)=\operatorname{Pr}\left(S_{2 t}=1, S_{2 t-1}=1 \mid S_{2 t-1}=1, S_{2 t-2}=2\right)=\operatorname{Pr}\left(S_{2 t}=1 \mid S_{2 t-1}=1\right)=q_{11}
\end{aligned}
$$

There is a unique correspondence between the states of $S_{3 t}$ process and states of $S_{2 t}$ process. The process $S_{2 t}$ is in state 1 if the $S_{3 t}$ process is either in state 1 or 2 and the process $S_{2 t}$ is in state 2 if the $S_{3 t}$ process is either in state 3 or 4 . Therefore, drawing of the states of $S_{3 t}$ process is equivalent to drawing of the states of $S_{2 t}$ process. The values that $S_{3 t}$ takes across the four possible states are presented in Table 14.

We denote the state space model (A8) - (A11) with the Markov processes $S_{1 t}, S_{3 t}$ as the state space model 1 (SPM1).

Note that the permanent and transitory components $c_{t}$ and $x_{t}$ enter the state-space model (A8) - (A11) in the differenced form. Once we make the draws of $\Upsilon,\left\{S_{1 t}\right\}_{t=1}^{T},\left\{S_{2 t}\right\}_{t=1}^{T}$, 
$\left\{\xi_{t}\right\}_{t=1}^{T}$, we propose to use another state-space representation of the model (A1) - (A6) for estimation the levels of the permanent and transitory components. We denote this state space model as state space model 2 (SPM2):

$$
\begin{aligned}
\triangle y_{t}^{*} & =\hat{H} \hat{\xi}_{t}+\zeta \triangle z_{t}^{*}+E_{t} \\
\hat{\xi}_{t} & =\hat{\alpha}_{S_{1 t}, S_{2 t}}+\hat{F} \xi_{t-1}+\hat{V}_{t} \\
E\left(V_{t} V_{t}^{\prime}\right) & =\hat{Q} \\
E\left(E_{t} E_{t}^{\prime}\right) & =\hat{R}
\end{aligned}
$$

where $\triangle y_{t}^{*}, \triangle z_{t}^{*}, \zeta, E_{t}$ are defined as in model SPM1. Other variables in the model SPM2 are defined as follows:

$$
\begin{gathered}
\hat{\xi}_{t}=\left[\begin{array}{c}
c_{t} \\
x_{t} \\
c_{t-1} \\
x_{t-1} \\
c_{t-2} \\
x_{t-2}
\end{array}\right], \hat{\alpha}_{S_{1 t}, S_{2 t}}=\left[\begin{array}{c}
\mu_{S_{1 t}} \\
\tau_{t, S_{2 t}} \\
0 \\
0 \\
0 \\
0
\end{array}\right], \hat{V}_{t}=\left[\begin{array}{c}
v_{t} \\
u_{t} \\
0 \\
0 \\
0 \\
0
\end{array}\right] \\
\hat{H}=\left[\begin{array}{lllll}
\gamma_{1} & \lambda_{1} & -\gamma_{1} \psi_{1} & -\lambda_{1}\left(1+\psi_{1}\right) & \lambda_{1} \psi_{1} \\
\gamma_{2} & \lambda_{2} & -\gamma_{2} \psi_{2} & -\lambda_{2}\left(1+\psi_{2}\right) & \lambda_{2} \psi_{2} \\
\gamma_{3} & \lambda_{3} & -\gamma_{3} \psi_{3} & -\lambda_{3}\left(1+\psi_{3}\right) & \lambda_{3} \psi_{3} \\
\gamma_{4} & \lambda_{4} & -\gamma_{1} \psi_{1} & -\lambda_{4}\left(1+\psi_{4}\right) & \lambda_{4} \psi_{4}
\end{array}\right]
\end{gathered}
$$

and 


$$
\hat{F}=\left[\begin{array}{cccccc}
1+\phi & 0 & -\phi & 0 & 0 & 0 \\
0 & \phi^{*} & 0 & 0 & 0 & 0 \\
1 & 0 & 0 & 0 & 0 & 0 \\
0 & 1 & 0 & 0 & 0 & 0 \\
0 & 0 & 1 & 0 & 0 & 0 \\
0 & 0 & 0 & 1 & 0 & 0
\end{array}\right], \hat{Q}=\left[\begin{array}{cccccc}
1 & 0 & 0 & 0 & 0 & 0 \\
0 & \sigma_{u t}^{2} & 0 & 0 & 0 & 0 \\
0 & 0 & 0 & 0 & 0 & 0 \\
0 & 0 & 0 & 0 & 0 & 0 \\
0 & 0 & 0 & 0 & 0 & 0 \\
0 & 0 & 0 & 0 & 0 & 0
\end{array}\right]
$$

It is natural to ask at this point why we do not use the model SPM2 to draw the parameters $\Upsilon,\left\{S_{1 t}\right\}_{t=1}^{T},\left\{S_{2 t}\right\}_{t=1}^{T}$ together with $c_{t}$ and $x_{t}$ and use the model SPM1 to do that. The reason is that our Monte Carlo simulation experience shows that the estimate of the parameters in $\Upsilon$ are poor if the estimation is conducted using only SPM2 model. We believe that the reason for poor performance is the presence of stochastic trend in the level of the permanent component. The stochastic trends do not constitute a problem in Bayesian estimation and one may use the state space representation SPM2 for the estimation of the entire model. However, we have found in Monte Carlo simulations that a combination of two state-space models produces the best results.

\section{The Gibbs-sampling algorithm}

The Gibbs-sampling algorithm consists of several steps:

1. Conditional on the values of $\Upsilon$, the states $\left\{S_{1 t}\right\}_{t=1}^{T},\left\{S_{3 t}\right\}_{t=1}^{T}$, use the model SPM1 to draw the unobserved variables $\left\{\xi_{t}\right\}_{t=1}^{T}$. The conditional densities are presented in Kim and Nelson (1999).

2. Conditional on the values $\Upsilon, \xi_{t}$, use the model SPM1 to draw the unobserved states $\left\{S_{1 t}\right\}_{t=1}^{T}$ and $\left\{S_{3 t}\right\}_{t=1}^{T}$. The conditional densities are presented in Kim and Nelson (1999). 
3. Conditional on $\left\{\xi_{t}\right\}_{t=1}^{T}$, use the model SPM1 to draw the parameters $\gamma_{i}, \lambda_{i}, \sigma_{i}, \zeta_{i}$, $i=1,2,3,4$. The conditional densities are presented in Kim and Nelson (1999).

4. Conditional on $\left\{S_{1 t}\right\}_{t=1}^{T},\left\{S_{3 t}\right\}_{t=1}^{T},\left\{\xi_{t}\right\}_{t=1}^{T}$, use the model SPM1 to draw the parameters $\mu_{0}, \mu_{1}$ and $\tau$. The conditional densities are in Kim and Nelson (1999).

5. Conditional on $\Upsilon,\left\{\xi_{t}\right\}_{t=1}^{T}$, use the model SPM1 to draw the parameters $\psi_{i}, i=1,2,3,4$. The conditional densities are in Kim and Nelson (1999).

6. Conditional on $\left\{S_{1 t}\right\}_{t=1}^{T},\left\{S_{3 t}\right\}_{t=1}^{T},\left\{\xi_{t}\right\}_{t=1}^{T}, \mu_{0}, \mu_{1}, \tau, \frac{\sigma_{u 2}^{2}}{2 \sigma_{u 1}^{2}}$ use the model SPM1 to draw the parameters $\phi$ and $\phi^{*}$. The conditional densities are in Kim and Nelson (1999).

7. Use the the draws $\left\{S_{3 t}\right\}_{t=1}^{T}$ to construct the draws of $\left\{S_{2 t}\right\}_{t=1}^{T}$.

8. Conditional on $\left\{S_{1 t}\right\}_{t=1}^{T},\left\{S_{2 t}\right\}_{t=1}^{T}$, draw the parameters $p_{11}, p_{22}, q_{11}, q_{22}$. The conditional densities are in Kim and Nelson (1999).

9. Conditional on $\Upsilon,\left\{S_{1 t}\right\}_{t=1}^{T},\left\{S_{3 t}\right\}_{t=1}^{T}$, use the model SPM2 to draw the unobserved states $\left\{\hat{\xi}_{t}\right\}_{t=1}^{T}$

\section{References}

[1] Bernanke BS, Boivin J, Eliasz P (2003) Measuring the effects of monetary policy: a factor-augmented vector autoregressive (FAVAR) approach. Manuscript, Princeton University

[2] Bollerslev T, Zhang BYB (2003) Measuring and modeling systematic risk in factor pricing models using high-frequency data. Journal of Empirical Finance 10:533-558

[3] Cochrane JH (1994) Permanent and transitory components of GNP and stock prices. The Quarterly Journal of Economics 109:241 - 265 
[4] Clements MP, Krolzig HM (2002) Can oil shocks explain asymmetries in the US business cycle? Empirical Economics 27:185-204

[5] Diebold FX, Rudebusch GD (1996) Measuring business cycle: a modern perspective. The Review of Economics and Statistics 78:67-77

[6] Fama EF, French KR (1993) Common risk factors in the returns on stocks and bonds. Journal of Financial Economics 33:3-56

[7] Fama EF, French KR (1996) Multifactor explanations of asset pricing anomalies. Journal of Finance 51:55 - 184

[8] Forni M, Hallin M, Lippi M, Reichlin L (2000) The generalized dynamic factor model: identification and estimation. Review of Economics and Statistics 82:540-554

[9] Friedman M (1964) Monetary Studies of the National Bureau, the National Bureau enters its 45th Year, 44th Annual Report, 7-25 (NBER, New York); Reprinted in Friedman, M., 1969, The optimum quantity of money and other essays (Aldine, Chicago)

[10] Friedman M (1993) The "plucking model" of business fluctuations revisited. Economic Inquiry $31: 171-177$

[11] Fuhrer JC, Schuh S (1998) Beyond shocks: what causes business cycle? An overview. Conference Series, no. 42. Boston: Federal Reserve Bank of Boston

[12] Hamilton J (1983) Oil and the macroeconomy since World War II. Journal of Political Economy :228-248

[13] Hamilton J (1989) A new approach to the economic analysis of nonstationary time series and the business cycle. Econometrica 57:357-384 
[14] Hamilton J (1996) This is what happened to the oil price-macroeconomic relationship. Journal of Monetary Economics 38:215-220

[15] Hamilton J (2003) What is an oil shock? Journal of Econometrics 113: 363-398

[16] Hooker MA (1996) What happened to the oil price-macroeconomy relationship? Journal of Monetary Economics 38:195-213

[17] Kim C-J, Nelson CR (1999a) Friedman's plucking model of business fluctuations: test and estimation of permanent and transitory components. Journal of Money, Credit, and Banking 31:317-334

[18] Kim C-J, Nelson CR (1999b) Has the US economy become more stable? A Bayesian approach based on a Markov-switching model of the business cycle. The Review of Economics and Statistics 81:608-616

[19] Kim C-J, Nelson CR (1998) State-space models with regime switching: classical and Gibbs-sampling approaches with applications. The MIT press

[20] Kim C-J, Murray CJ (2002) Permanent and transitory components of recessions. Empirical Economics 27:163-183

[21] Kose MA, Otrok C, Whiteman CH (2003) International business cycles: world, region, and country-specific factors. The American Economic Review 93(4):1216 - 1239

[22] Kydland F, Prescott E (1982) Time to build and aggregate fluctuations. Econometrica 50:1345-1370

[23] Long J, Plosser C (1983) Real business cycles. Journal of Political Economy 91:39 -69

[24] Lucas RE (1987) Models of business cycles. New York. Basil Blackwell 
[25] Lucas (RE) (2003) Macroeconomic priorities. The American Economic Review $93(1): 1-14$

[26] Liew J, Vassalou M (2000) Can book-to-market, size and momentum be risk factors that predict economics growth? Journal of Financial Economics 57:221-245

[27] Leeper EM, Sims CA, Zha T (1996) What does monetary policy do? Brookings Papers on Economic Activity v0(2):1-63

[28] Marcellino M, Stock JH, Watson MW (2003) Macroeconomic forecasting in the Euro area: country specific versus area-wide information. European Economic Review 47:118

[29] McConnel MM, Perez-Quiros G (2000) Output fluctuations in the United States: what has changed since the early 1980's". American Economic Review, 90(5):14641476

[30] Mitchell WA (1927) Business cycles: The problem and its setting (NBER, New York)

[31] Raymond JE, Rich RW (1997) Oil and the macroeconomy: a Markov state-switching approach. Journal of Money, Credit, and Banking 29:193-213

[32] Sims C, (1998) The role of interest rate policy in the generation and propagation of business cycles: what has changed since the '30s? Conference Series, no. 42. Boston: Federal Reserve Bank of Boston

[33] Stock JH, Watson MW (2003) Has the business cycle changed? Evidence and explanations. Working paper

[34] Stock JH, Watson MW (2002a) Macroeconomic forecasting using diffusion indexes. Journal of Business and Economic Statistics 20(2):147 - 162 
[35] Stock JH, and Watson MW (2002b) Has the business cycle changed and why? Working paper

[36] Temin P, (1998) The causes of american business cycles: an essay in economic historiography. 
Table 1: Prior distribution for the model parameters

\begin{tabular}{lll}
\hline \hline$\pi\left(\gamma_{i}\right) \sim N(0,1), i=1 \ldots, n$ & $\pi\left(\lambda_{i}\right) \sim N(0,1), i=1 \ldots, n$ \\
$\pi\left(\zeta_{i}\right) \sim N(0,1), i=1 \ldots, n$ & $\pi\left(\sigma_{i j}^{2}\right) \sim \frac{1}{\sigma_{i}^{2}}, i=1 \ldots, n, j=1,2$ \\
$\pi\left(\mu_{0}\right) \sim N(0,1)$ & $\pi\left(\mu_{1}\right) \sim N(-0.5,1)_{(-\infty, 0)}^{(\mathrm{a})}$ \\
$\pi(\tau) \sim N(-3.5,1)_{(-\infty, 0)}$ & $\pi\left(\psi_{i}\right) \sim N(0,0.5), i=1 \ldots, n$ \\
$\pi(\phi) \sim N(0,0.25)_{(-1,1)}$ & $\pi\left(\phi^{*}\right) \sim N(0,0.25)_{(-1,1)}$ \\
$\pi\left(p_{11}\right) \sim B e(9,1)$ & $\pi\left(p_{22}\right) \sim B e(8,2)$ \\
$\pi\left(q_{11}\right) \sim B e(9,1)$ & $\pi\left(q_{22}\right) \sim B e(8,2)$ \\
\hline
\end{tabular}

(a) The notation $N(., .)_{(a, b)}$ means that a parameter has truncated normal distribution with the support $(a, b)$. 
Table 2: The estimates of the conditional variance for the benchmark model, monthly data, 1959.01 - 2002.12

\begin{tabular}{ccccccccccccc}
\hline \hline & \multicolumn{1}{c}{ Period I* } & \multicolumn{1}{c}{ Period II** } \\
\hline & $\sigma_{\triangle c_{t}}^{2}$ & $\sigma_{\triangle x_{t}}^{2}$ & $\sigma_{1}^{2}$ & $\sigma_{2}^{2}$ & $\sigma_{3}^{2}$ & $\sigma_{4}^{2}$ & $\sigma_{\triangle c_{t}}^{2}$ & $\sigma_{\triangle x_{t}}^{2}$ & $\sigma_{1}^{2}$ & $\sigma_{2}^{2}$ & $\sigma_{3}^{2}$ & $\sigma_{4}^{2}$ \\
$\mathrm{BM}$ & 20.82 & 1.77 & 0.20 & 0.09 & 0.68 & 0.02 & 14.17 & 0.20 & 0.12 & 0.11 & 0.68 & 0.004 \\
& & & $(0.04)$ & $(0.00)$ & $(0.05)$ & $(0.00)$ & & & $(0.02)$ & $(0.00)$ & $(0.05)$ & $(0.00)$ \\
\hline \multirow{2}{*}{ Oil } & 24.86 & 1.83 & 0.20 & 0.09 & 0.68 & 0.02 & 17.33 & 0.21 & 0.12 & 0.11 & 0.68 & 0.004 \\
& & & $(0.04)$ & $(0.00)$ & $(0.05)$ & $(0.00)$ & & & $(0.02)$ & $(0.00)$ & $(0.05)$ & $(0.00)$ \\
\hline \multirow{2}{*}{$\mathrm{R}$} & 20.63 & 1.67 & 0.19 & 0.09 & 0.67 & 0.02 & 14.16 & 0.20 & 0.11 & 0.11 & 0.66 & 0.004 \\
& & & $(0.04)$ & $(0.00)$ & $(0.05)$ & $(0.00)$ & & & $(0.02)$ & $(0.00)$ & $(0.05)$ & $(0.00)$ \\
\hline \multirow{2}{*}{ DJ } & 23.27 & 1.75 & 0.20 & 0.09 & 0.68 & 0.02 & 16.02 & 0.21 & 0.11 & 0.11 & 0.66 & 0.004 \\
& & & $(0.04)$ & $(0.00)$ & $(0.05)$ & $(0.00)$ & & & $(0.02)$ & $(0.00)$ & $(0.05)$ & $(0.00)$ \\
\hline
\end{tabular}

* Period I reefers to the period 1959:01 - 1983:12

** Period II reefers to the period 1984:01 - 2002:12 
Table 3: The estimates of the parameters, monthly data, 1959.01 - 2002.12

\begin{tabular}{|c|c|c|c|c|}
\hline & $\begin{array}{c}\text { Benchmark } \\
\text { model }\end{array}$ & $\begin{array}{c}\text { Oil } \\
\text { Price }\end{array}$ & $\begin{array}{c}\text { Interest } \\
\text { Rate }\end{array}$ & $\begin{array}{c}\text { DJ } \\
\text { Returns }\end{array}$ \\
\hline \multicolumn{5}{|c|}{ Transition Probabilities } \\
\hline$p_{11}$ & $\begin{array}{c}0.951 \\
(0.018)\end{array}$ & $\begin{array}{c}0.954 \\
(0.017)\end{array}$ & $\begin{array}{c}0.954 \\
(0.017)\end{array}$ & $\begin{array}{c}0.954 \\
(0.017)\end{array}$ \\
\hline$p_{22}$ & $\begin{array}{c}0.818 \\
(0.068)\end{array}$ & $\begin{array}{c}0.842 \\
(0.060)\end{array}$ & $\begin{array}{c}0.835 \\
(0.063)\end{array}$ & $\begin{array}{c}0.838 \\
(0.061)\end{array}$ \\
\hline$q_{11}$ & $\begin{array}{c}0.971 \\
(0.013)\end{array}$ & $\begin{array}{c}0.969 \\
(0.013)\end{array}$ & $\begin{array}{c}0.973 \\
(0.013)\end{array}$ & $\begin{array}{c}0.971 \\
(0.013)\end{array}$ \\
\hline$q_{22}$ & $\begin{array}{c}0.504 \\
(0.183)\end{array}$ & $\begin{array}{c}0.509 \\
(0.180)\end{array}$ & $\begin{array}{c}0.489 \\
(0.175)\end{array}$ & $\begin{array}{c}0.514 \\
(0.186)\end{array}$ \\
\hline \multicolumn{5}{|c|}{ Regime Dependent Parameters } \\
\hline$\mu_{0, I}$ & $\begin{array}{c}1.185 \\
(0.335)\end{array}$ & $\begin{array}{c}1.332 \\
(0.304)\end{array}$ & $\begin{array}{c}1.204 \\
(0.326)\end{array}$ & $\begin{array}{c}1.262 \\
(0.291)\end{array}$ \\
\hline$\mu_{1, I}$ & $\begin{array}{l}-2.226 \\
(0.582)\end{array}$ & $\begin{array}{l}-2.332 \\
(0.573)\end{array}$ & $\begin{array}{l}-2.118 \\
(0.565)\end{array}$ & $\begin{array}{l}-2.278 \\
(0.557)\end{array}$ \\
\hline$\mu_{0, I I}$ & $\begin{array}{c}0.730 \\
(0.202)\end{array}$ & $\begin{array}{c}0.808 \\
(0.189)\end{array}$ & $\begin{array}{c}0.742 \\
(0.195)\end{array}$ & $\begin{array}{c}0.767 \\
(0.187)\end{array}$ \\
\hline$\mu_{1, I I}$ & $\begin{array}{l}-1.813 \\
(0.455)\end{array}$ & $\begin{array}{l}-1.906 \\
(0.428)\end{array}$ & $\begin{array}{l}-1.754 \\
(0.402)\end{array}$ & $\begin{array}{l}-1.863 \\
(0.392)\end{array}$ \\
\hline$\tau_{1}$ & $\begin{array}{l}-4.148 \\
(0.609)\end{array}$ & $\begin{array}{l}-4.142 \\
(0.565)\end{array}$ & $\begin{array}{l}-4.185 \\
(0.605)\end{array}$ & $\begin{array}{l}-4.105 \\
(0.577)\end{array}$ \\
\hline$\tau_{2}$ & $\begin{array}{c}-1.677 \\
(0.346)\end{array}$ & $\begin{array}{l}-1.667 \\
(0.350)\end{array}$ & $\begin{array}{l}-1.673 \\
(0.319)\end{array}$ & $\begin{array}{l}-1.663 \\
(0.347)\end{array}$ \\
\hline$\frac{\sigma_{v, 2}^{2}}{\sigma_{v, 1}^{2}}$ & $\begin{array}{c}0.394 \\
(0.244)\end{array}$ & $\begin{array}{c}0.495 \\
(0.274)\end{array}$ & $\begin{array}{c}0.411 \\
(0.223)\end{array}$ & $\begin{array}{c}0.446 \\
(0.232)\end{array}$ \\
\hline$\frac{\sigma_{u, 2}^{2}}{\sigma_{u, 1}^{2}}$ & $\begin{array}{c}0.184 \\
(0.055)\end{array}$ & $\begin{array}{c}0.190 \\
(0.054)\end{array}$ & $\begin{array}{c}0.190 \\
(0.047)\end{array}$ & $\begin{array}{c}0.193 \\
(0.054)\end{array}$ \\
\hline
\end{tabular}


Table 4: The estimates of the parameters, monthly data, $1959.01-2002.12$

\begin{tabular}{|c|c|c|c|c|}
\hline & $\begin{array}{c}\text { Benchmark } \\
\text { model }\end{array}$ & $\begin{array}{c}\text { Oil } \\
\text { Price }\end{array}$ & $\begin{array}{c}\text { Interest } \\
\text { Rate }\end{array}$ & $\begin{array}{c}\text { DJ } \\
\text { Returns }\end{array}$ \\
\hline \multicolumn{5}{|c|}{ Permanent Factor Loadings } \\
\hline \multirow[t]{2}{*}{$\gamma_{1}$} & 0.051 & 0.045 & 0.049 & 0.047 \\
\hline & $(0.012)$ & $(0.010)$ & $(0.012)$ & $(0.010)$ \\
\hline \multirow{2}{*}{$\gamma_{2}$} & 0.045 & 0.040 & 0.044 & 0.041 \\
\hline & $(0.010)$ & $(0.008)$ & $(0.009)$ & $(0.008)$ \\
\hline \multirow[t]{2}{*}{$\gamma_{3}$} & 0.046 & 0.040 & 0.047 & 0.041 \\
\hline & $(0.011)$ & $(0.010)$ & $(0.011)$ & $(0.009)$ \\
\hline \multirow[t]{2}{*}{$\gamma_{4}$} & 0.033 & 0.029 & 0.032 & 0.030 \\
\hline & $(0.007)$ & $(0.006)$ & $(0.006)$ & $(0.006)$ \\
\hline \multicolumn{5}{|c|}{ Transitory Factor Loadings } \\
\hline \multirow[t]{2}{*}{$\lambda_{1}$} & 0.569 & 0.560 & 0.582 & 0.571 \\
\hline & $(0.064)$ & $(0.062)$ & $(0.052)$ & $(0.059)$ \\
\hline \multirow[t]{2}{*}{$\lambda_{2}$} & 0.164 & 0.162 & 0.165 & 0.164 \\
\hline & $(0.018)$ & $(0.018)$ & $(0.017)$ & $(0.017)$ \\
\hline \multirow[t]{2}{*}{$\lambda_{3}$} & 0.459 & 0.451 & 0.479 & 0.456 \\
\hline & $(0.050)$ & $(0.048)$ & $(0.044)$ & $(0.047)$ \\
\hline \multirow[t]{2}{*}{$\lambda_{4}$} & 0.099 & 0.099 & 0.098 & 0.099 \\
\hline & $(0.010)$ & $(0.010)$ & $(0.009)$ & $(0.010)$ \\
\hline \multicolumn{5}{|c|}{ Autoregressive parameter for the Common Component } \\
\hline \multirow[t]{2}{*}{$\phi$} & 0.894 & 0.895 & 0.894 & 0.894 \\
\hline & $(0.024)$ & $(0.023)$ & $(0.022)$ & $(0.027)$ \\
\hline \multirow[t]{2}{*}{$\phi^{*}$} & 0.453 & 0.466 & 0.433 & 0.448 \\
\hline & $(0.064)$ & $(0.068)$ & $(0.062)$ & $(0.064)$ \\
\hline \multicolumn{5}{|c|}{ Autoregressive parameter for the Idiosyncratic Component } \\
\hline \multirow[t]{2}{*}{$\psi_{1}$} & -0.047 & -0.056 & -0.054 & -0.048 \\
\hline & $(0.061)$ & $(0.061)$ & $(0.061)$ & $(0.061)$ \\
\hline \multirow[t]{2}{*}{$\psi_{2}$} & -0.007 & -0.017 & -0.012 & -0.007 \\
\hline & $(0.049)$ & $(0.048)$ & $(0.048)$ & $(0.048)$ \\
\hline \multirow[t]{2}{*}{$\psi_{3}$} & -0.322 & -0.322 & -0.331 & -0.333 \\
\hline & $(0.043)$ & $(0.044)$ & $(0.043)$ & $(0.043)$ \\
\hline \multirow[t]{2}{*}{$\psi_{4}$} & -0.218 & -0.207 & -0.219 & -0.220 \\
\hline & $(0.055)$ & $(0.058)$ & $(0.056)$ & $(0.057)$ \\
\hline \multicolumn{5}{|c|}{ Third Factor Loadings } \\
\hline \multirow[t]{2}{*}{$\zeta_{1}$} & - & -0.0050 & 0.089 & 0.0014 \\
\hline & & $(0.0049)$ & $(0.066)$ & $(0.005)$ \\
\hline \multirow[t]{2}{*}{$\zeta_{2}$} & - & -0.0090 & 340.015 & 0.0010 \\
\hline & & $(0.0029)$ & $(0.028)$ & $(0.003)$ \\
\hline \multirow[t]{2}{*}{$\zeta_{3}$} & - & -0.0026 & -0.090 & 0.020 \\
\hline & & $(0.0074)$ & $(0.072)$ & $(0.008)$ \\
\hline \multirow[t]{2}{*}{$\zeta_{4}$} & - & -0.0017 & 0.033 & -0.0019 \\
\hline & & $(0.0011)$ & $(0.014)$ & $(0.0012)$ \\
\hline
\end{tabular}


Table 5: The variance decomposition: Benchmark Model, 1959:01-2002:12

\begin{tabular}{ccccccc}
\hline \hline & \multicolumn{3}{c}{$\begin{array}{c}\text { Percentage of total variance attributed to } \\
\text { permanent } \\
\text { component }\end{array}$} & \multicolumn{2}{c}{$\begin{array}{c}\text { transitory } \\
\text { component }\end{array}$} & \multicolumn{2}{c}{$\begin{array}{c}\text { idiosyncratic } \\
\text { component }\end{array}$} \\
& I & II & I & II & I & II \\
\hline Industrial Production & $4.05 \%$ & $27.44 \%$ & $69.09 \%$ & $32.58 \%$ & $26.85 \%$ & $39.96 \%$ \\
Personal Income & $14.39 \%$ & $68.85 \%$ & $26.97 \%$ & $8.99 \%$ & $58.62 \%$ & $22.15 \%$ \\
Manufacturing and & & & & & & \\
Trade Sales & $2.33 \%$ & $24.42 \%$ & $32.27 \%$ & $23.52 \%$ & $65.38 \%$ & $52.05 \%$ \\
Employment & $24.32 \%$ & $78.34 \%$ & $30.82 \%$ & $6.91 \%$ & $44.85 \%$ & $14.73 \%$ \\
\hline
\end{tabular}


Table 6: The volatility decline decomposition: Benchmark Model, 1959:012002:12

\begin{tabular}{cccc}
\hline \hline & \multicolumn{3}{c}{ Percentage of variance decline attributed to } \\
& $\begin{array}{c}\text { permanent } \\
\text { component }\end{array}$ & $\begin{array}{c}\text { transitory } \\
\text { component }\end{array}$ & $\begin{array}{c}\text { idiosyncratic component } \\
\text { component }\end{array}$ \\
\hline Industrial Production & $0.19 \%$ & $75.11 \%$ & $24.70 \%$ \\
Personal Income & $0.75 \%$ & $31.48 \%$ & $67.77 \%$ \\
Manufacturing and & & & \\
Trade Sales & $0.10 \%$ & $33.15 \%$ & $66.75 \%$ \\
Employment & $1.44 \%$ & $40.94 \%$ & $57.62 \%$ \\
\hline
\end{tabular}


Table 7: The variance decomposition: Oil Model, 1959:01-2002:12

\begin{tabular}{|c|c|c|c|c|c|c|c|c|}
\hline & \multicolumn{8}{|c|}{ Percentage of total variance attributed to } \\
\hline & \multirow{2}{*}{\multicolumn{2}{|c|}{$\begin{array}{l}\text { permanent } \\
\text { component }\end{array}$}} & \multirow{2}{*}{\multicolumn{2}{|c|}{$\begin{array}{l}\text { transitory } \\
\text { component }\end{array}$}} & \multirow{2}{*}{\multicolumn{2}{|c|}{$\begin{array}{c}\text { oil } \\
\text { prices }\end{array}$}} & \multirow{2}{*}{\multicolumn{2}{|c|}{$\begin{array}{c}\text { idiosyncratic } \\
\text { component }\end{array}$}} \\
\hline & & & & & & & & \\
\hline & $I^{1}$ & II & I & II & $I^{1}$ & II & $I^{1}$ & II \\
\hline Industrial Production & $4.14 \%$ & $19.02 \%$ & $79.84 \%$ & $32.58 \%$ & $0.78 \%$ & $2.63 \%$ & $14.96 \%$ & $52.60 \%$ \\
\hline Personal Income & $22.25 \%$ & $22.91 \%$ & $33.82 \%$ & $8.99 \%$ & $6.02 \%$ & $4.51 \%$ & $37.95 \%$ & $69.90 \%$ \\
\hline \multicolumn{9}{|l|}{ Manufacturing and } \\
\hline Trade Sales & $2.35 \%$ & $3.37 \%$ & $48.36 \%$ & $23.52 \%$ & $0.12 \%$ & $0.12 \%$ & $49.07 \%$ & $91.62 \%$ \\
\hline Employment & $31.26 \%$ & $76.36 \%$ & $42.20 \%$ & $6.91 \%$ & $0.87 \%$ & $1.55 \%$ & $25.69 \%$ & $14.62 \%$ \\
\hline
\end{tabular}

Table 8: The volatility decline decomposition: Oil Model, 1959:01-2002:12

\begin{tabular}{ccccc}
\hline \hline & \multicolumn{3}{c}{ Percentage of variance } & decline attributed to \\
permanent & transitory & Oil & idiosyncratic \\
& component & component & prices & component \\
\hline Industrial Production & $1.55 \%$ & $89.22 \%$ & $0.46 \%$ & $8.42 \%$ \\
Personal Income & $20.96 \%$ & $94.83 \%$ & $8.95 \%$ & $-24.26 \%$ \\
Manufacturing and & & & & \\
Trade Sales & $1.43 \%$ & $87.74 \%$ & $0.11 \%$ & $10.53 \%$ \\
Employment & $13.86 \%$ & $55.68 \%$ & $0.61 \%$ & $29.97 \%$ \\
\hline
\end{tabular}


Table 9: The variance decomposition: Interest Rate Model, 1959:01-2002:12

\begin{tabular}{ccccccccc}
\hline \hline & \multicolumn{8}{c}{ Percentage of total variance attributed to } \\
& $\begin{array}{c}\text { permanent } \\
\text { component }\end{array}$ & \multicolumn{2}{c}{$\begin{array}{c}\text { transitory } \\
\text { component }\end{array}$} & \multicolumn{2}{c}{$\begin{array}{c}\text { Interest } \\
\text { Rate }\end{array}$} & \multicolumn{2}{c}{$\begin{array}{c}\text { idiosyncratic } \\
\text { component }\end{array}$} \\
& I & II & I & II & I & II & I & II \\
\hline Industrial Production & $2.18 \%$ & $5.93 \%$ & $77.88 \%$ & $47.59 \%$ & $1.20 \%$ & $0.35 \%$ & $16.12 \%$ & $45.47 \%$ \\
Personal Income & $13.56 \%$ & $9.77 \%$ & $32.12 \%$ & $5.19 \%$ & $0.00 \%$ & $0.00 \%$ & $54.28 \%$ & $85.02 \%$ \\
Manufacturing and & & & & & & & & \\
Trade Sales & $1.30 \%$ & $1.30 \%$ & $43.06 \%$ & $9.62 \%$ & $0.39 \%$ & $0.04 \%$ & $56.35 \%$ & $89.13 \%$ \\
Employment & $17.51 \%$ & $44.73 \%$ & $38.22 \%$ & $21.93 \%$ & $2.49 \%$ & $0.70 \%$ & $36.85 \%$ & $27.65 \%$ \\
\hline
\end{tabular}

Table 10: The volatility decline decomposition: Interest Rate Model, 1959:01-2002:12

\begin{tabular}{ccccc}
\hline \hline & \multicolumn{3}{c}{ Percentage of variance } & decline attributed to \\
permanent & transitory & interest & idiosyncratic \\
component & component & rate & component \\
\hline Industrial Production & $1.25 \%$ & $85.37 \%$ & $1.40 \%$ & $8.87 \%$ \\
Personal Income & $24.83 \%$ & $121.10 \%$ & $0.00 \%$ & $-36.98 \%$ \\
Manufacturing and & & & & \\
Trade Sales & $1.31 \%$ & $82.56 \%$ & $0.80 \%$ & $17.63 \%$ \\
Employment & $10.23 \%$ & $42.48 \%$ & $2.97 \%$ & $39.31 \%$ \\
\hline
\end{tabular}


Table 11: The variance decomposition: DJ Returns Model, 1959:01-2002:12

\begin{tabular}{ccccccccc}
\hline \hline & \multicolumn{8}{c}{ Percentage of total variance attributed to } \\
& $\begin{array}{c}\text { permanent } \\
\text { component }\end{array}$ & \multicolumn{2}{c}{ transitory } & \multicolumn{2}{c}{ DJ } & \multicolumn{2}{c}{ idiosyncratic } \\
& component & \multicolumn{2}{c}{ Returns } & \multicolumn{2}{c}{ component } \\
& I & II & I & II & I & II & I & II \\
\hline Industrial Production & $3.27 \%$ & $22.12 \%$ & $78.35 \%$ & $25.48 \%$ & $0.04 \%$ & $0.22 \%$ & $18.44 \%$ & $54.30 \%$ \\
Personal Income & $9.90 \%$ & $16.84 \%$ & $38.72 \%$ & $3.17 \%$ & $0.00 \%$ & $0.00 \%$ & $51.34 \%$ & $79.76 \%$ \\
Manufacturing and & & & & & & & & \\
Trade Sales & $1.91 \%$ & $3.65 \%$ & $42.95 \%$ & $3.95 \%$ & $0.84 \%$ & $1.35 \%$ & $53.86 \%$ & $88.95 \%$ \\
Employment & $23.50 \%$ & $77.40 \%$ & $35.04 \%$ & $5.56 \%$ & $0.49 \%$ & $1.36 \%$ & $41.00 \%$ & $21.18 \%$ \\
\hline
\end{tabular}

Table 12: The volatility decline decomposition: DJ Returns Model, 1959:012002:12

\begin{tabular}{ccccc}
\hline \hline & \multicolumn{3}{c}{ Percentage of variance } & decline attributed to \\
& permanent & transitory & DJ & idiosyncratic \\
& component & component & returns & component \\
\hline Industrial Production & $-1.11 \%$ & $90.69 \%$ & $-0.00 \%$ & $10.08 \%$ \\
Personal Income & $-11.01 \%$ & $145.99 \%$ & $-0.00 \%$ & $-34.38 \%$ \\
Manufacturing and & & & & \\
Trade Sales & $-1.59 \%$ & $121.59 \%$ & $-0.19 \%$ & $-16.87 \%$ \\
Employment & $-10.62 \%$ & $53.71 \%$ & $-0.06 \%$ & $53.54 \%$ \\
\hline
\end{tabular}


Table 13: Definition of states for $S_{3 t}$ process

\begin{tabular}{ccc}
\hline \hline$S_{3 t}$ states & $S_{2 t}$ states & $S_{2 t-1}$ states \\
\hline 1 & 1 & 2 \\
2 & 1 & 1 \\
3 & 2 & 2 \\
4 & 2 & 1 \\
\hline
\end{tabular}


Table 14: Values of $S_{3 t}$ process across the states

\begin{tabular}{cc}
\hline \hline$S_{3 t}$ states & $S_{3 t}$ values \\
\hline 1 & -1 \\
2 & 0 \\
3 & 0 \\
4 & 1 \\
\hline
\end{tabular}


Common Permanent Component, 1959:03 - 2002:12

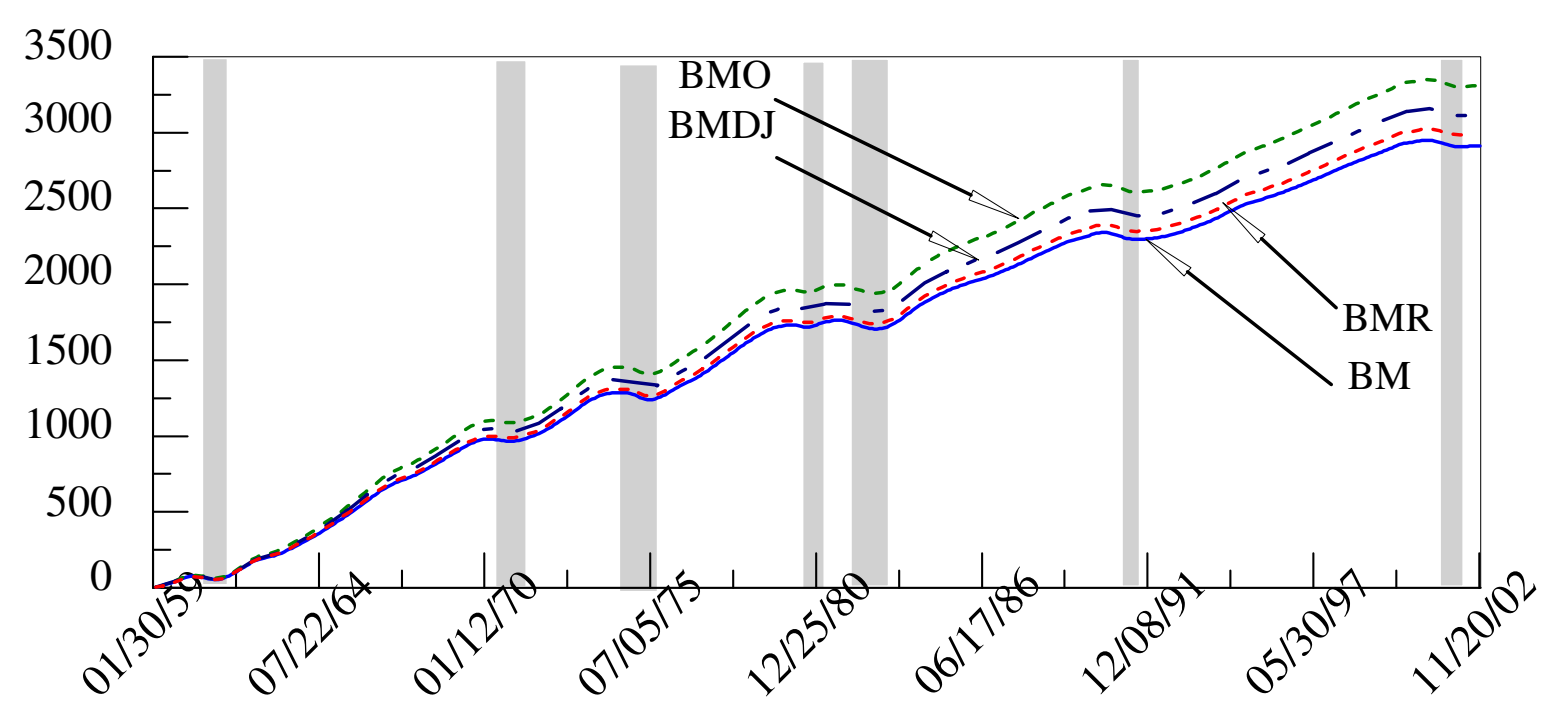

Common transitory component, 1959:03 - 2002:12

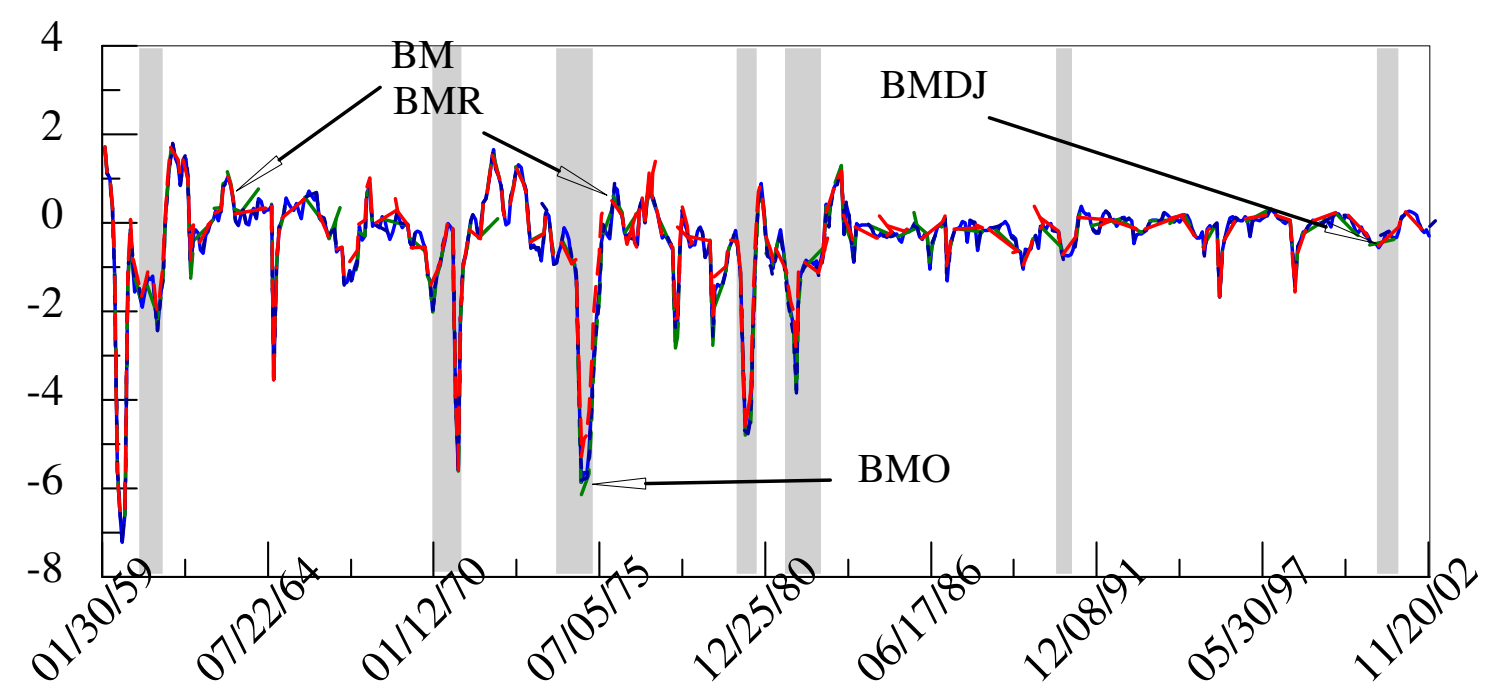

Figure 1: Permanent and transitory components of recessions, the sample period in the estimation 1959:03 - 2002:12. The notation is as follows: BM - two factor model (benchmark model), BMDJ - three factor model with the returns on stock market, BMR - three factor model with the interest rate, BMO - three factor model with oil prices. 
Smoothed Probability that $\mathrm{C}$
1959:03-2002:12

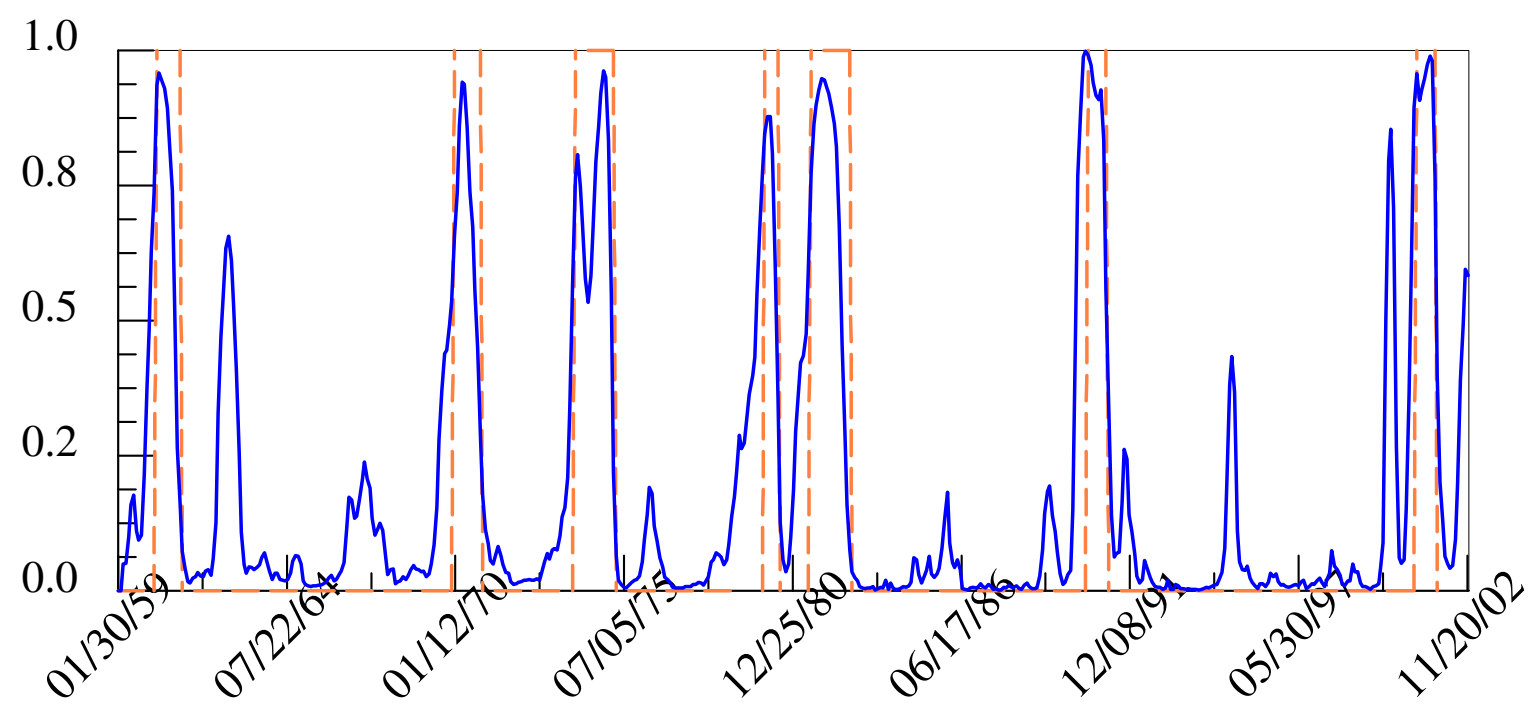

Smoothed Probability that $\mathrm{x} \quad \mathrm{t}$ is contracting, 1959:03 - 2002:12

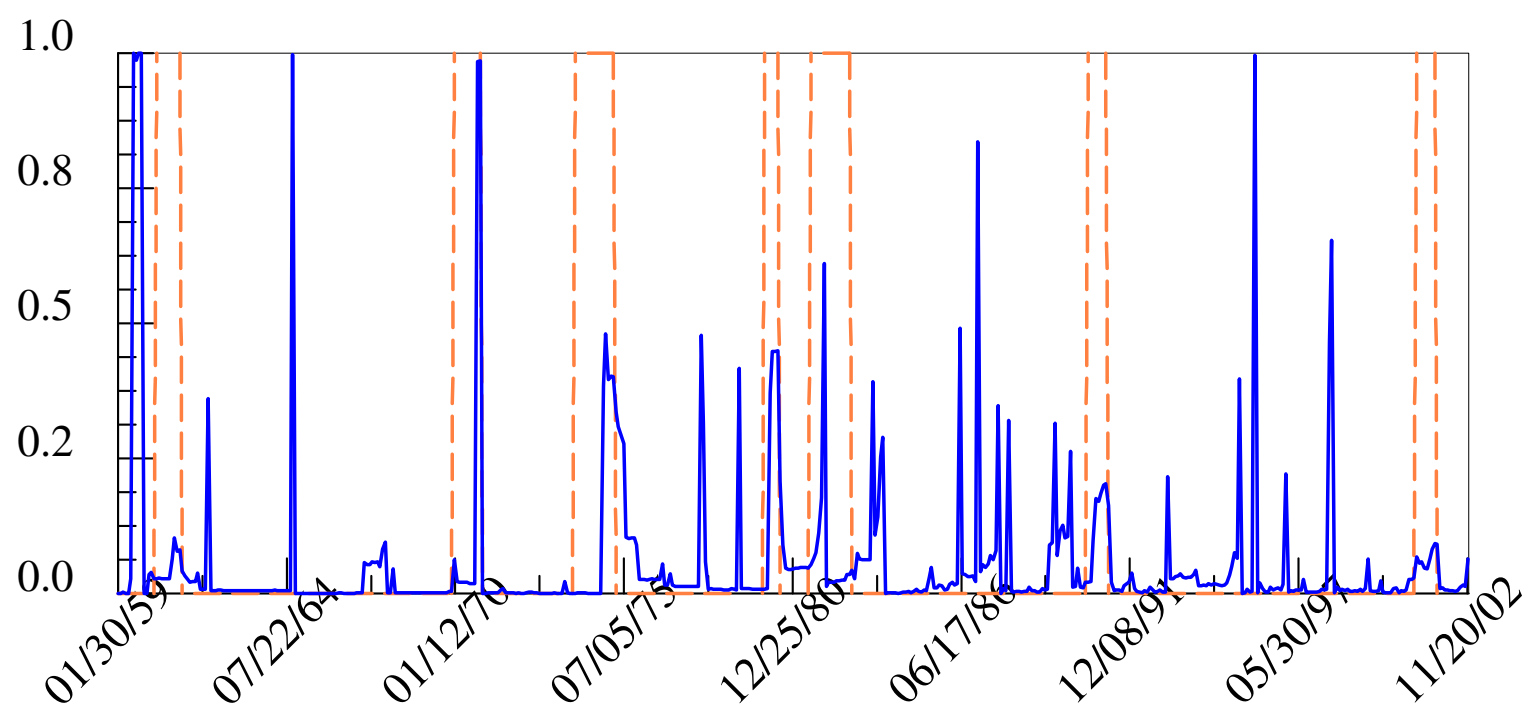

43

Figure 2: The smoothed probabilities of contraction in the permanent and transitory components, the sample period in the estimation 1959:03 - 2002:12. 
Common Permanent Component, 1959:03 - 2002:12

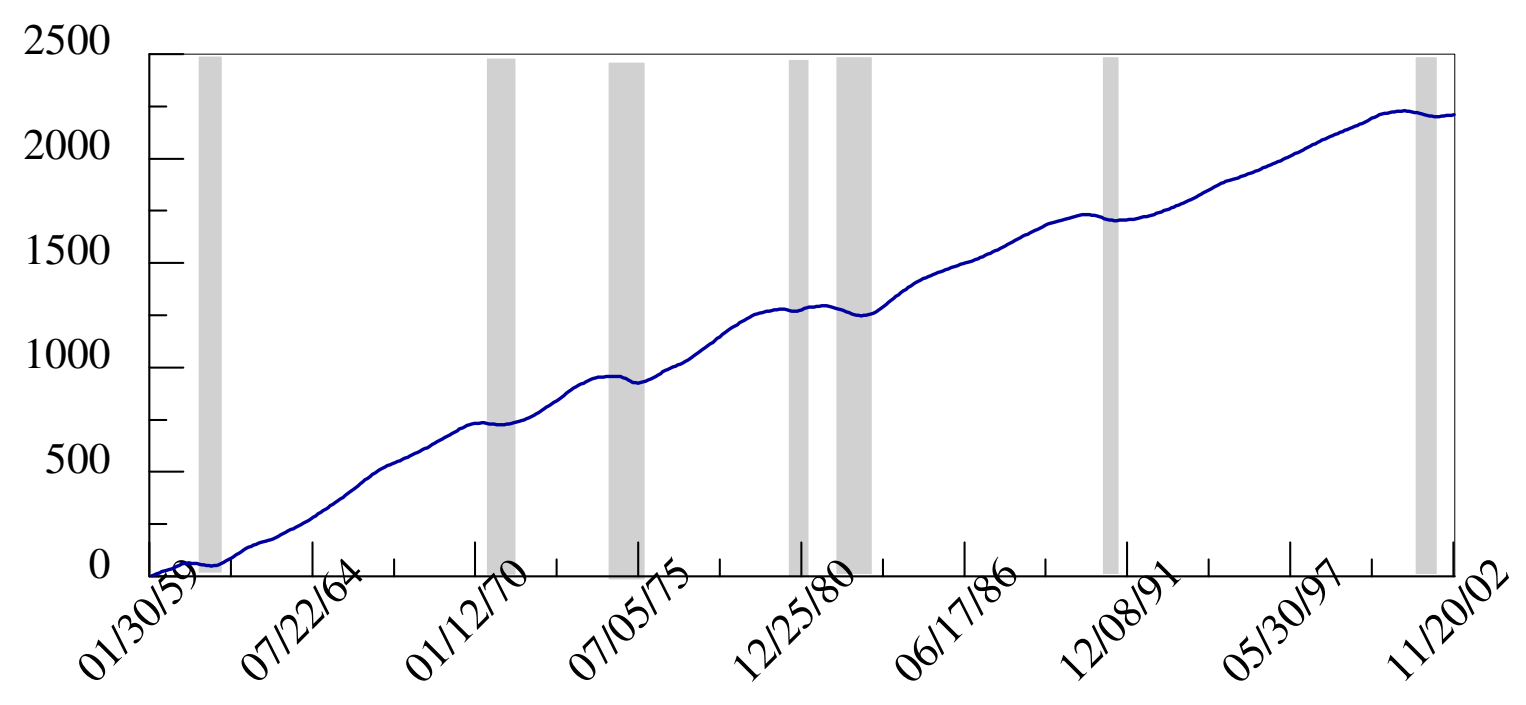

Common transitory component, 1959:03 - 2002:12

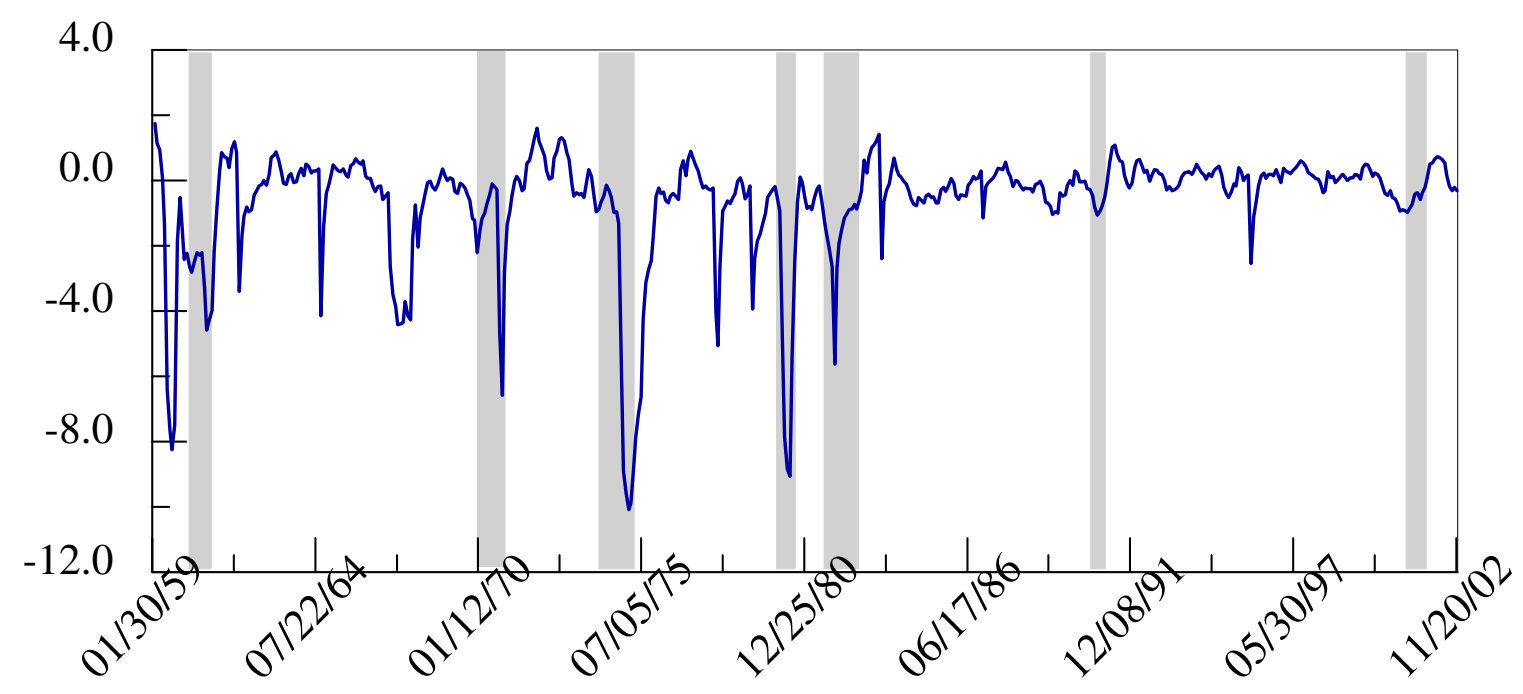

Figure 3: Permanent and transitory components of recessions, the sample period in the estimation 1959:03 - 2002:12. Estimate of Kim and Murray (2002) model. 
Smoothed Probability that $\mathrm{C}$
1959:03-2002:12

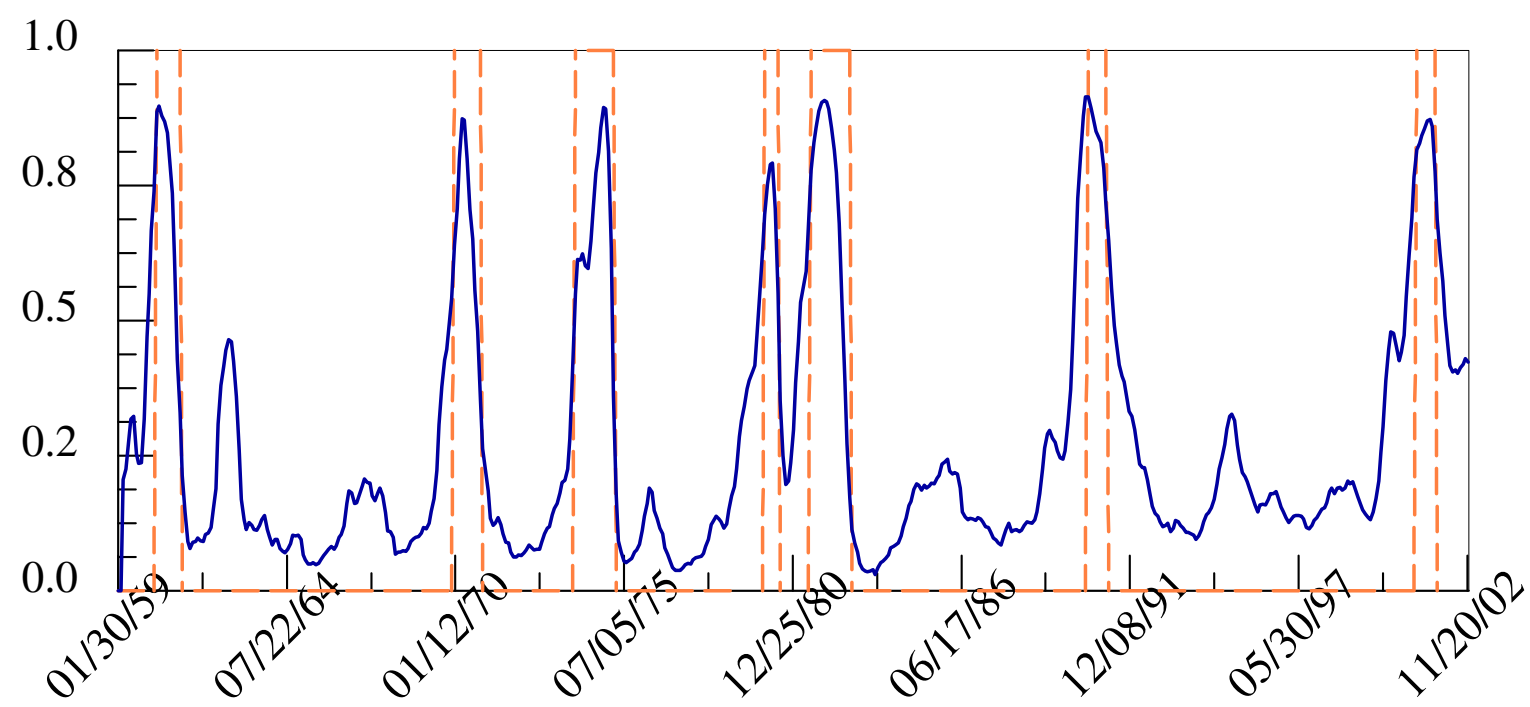

Smoothed Probability that $\mathrm{x} \mathrm{t}_{\mathrm{t}}$ is contracting, 1959:03 - 2002:12

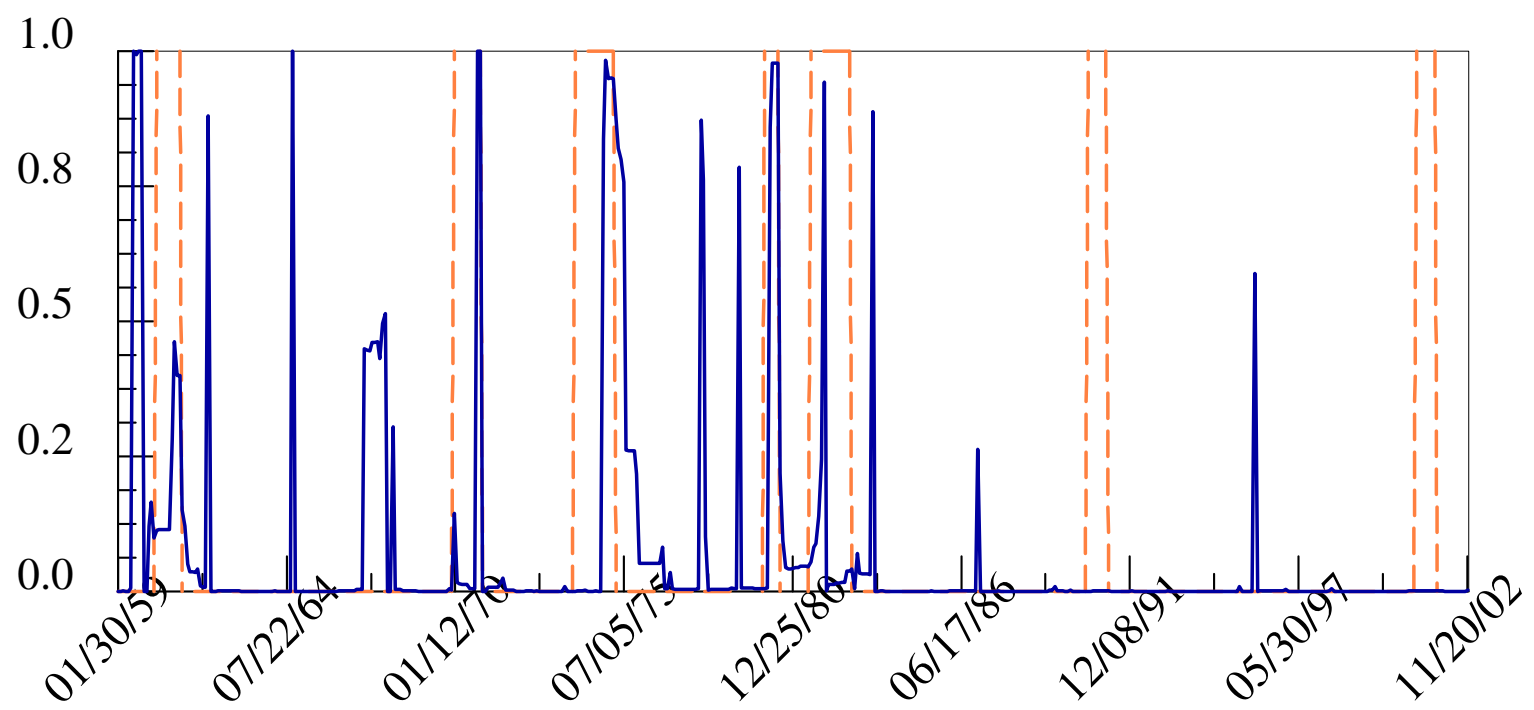

45

Figure 4: The smoothed probabilities of contraction in the permanent and transitory components, the sample period in the estimation 1959:03 - 2002:12. Estimates of Kim and Murray (2002) model. 